Review

\title{
Graphene Quantum Dots as Flourishing Nanomaterials for Bio-Imaging, Therapy Development, and Micro-Supercapacitors
}

\author{
Merve Kortel@ ${ }^{\oplus}$, Bhargav D. Mansuriya, Nicole Vargas Santana and Zeynep Altintas * \\ Technical University of Berlin, Straße des 17. Juni 124, 10623 Berlin, Germany; mervekortel@gmail.com (M.K.); \\ b.mansuriya@campus.tu-berlin.de (B.D.M.); n.vargassantana@campus.tu-berlin.de (N.V.S.) \\ * Correspondence: zeynep.altintas@tu-berlin.de
}

Received: 19 August 2020; Accepted: 16 September 2020; Published: 18 September 2020

check for updates

\begin{abstract}
Graphene quantum dots (GQDs) are considerably a new member of the carbon family and shine amongst other members, thanks to their superior electrochemical, optical, and structural properties as well as biocompatibility features that enable us to engage them in various bioengineering purposes. Especially, the quantum confinement and edge effects are giving GQDs their tremendous character, while their heteroatom doping attributes enable us to specifically and meritoriously tune their prospective characteristics for innumerable operations. Considering the substantial role offered by GQDs in the area of biomedicine and nanoscience, through this review paper, we primarily focus on their applications in bio-imaging, micro-supercapacitors, as well as in therapy development. The size-dependent aspects, functionalization, and particular utilization of the GQDs are discussed in detail with respect to their distinct nano-bio-technological applications.
\end{abstract}

Keywords: graphene quantum dots (GQDs); nanomaterials; bio-imaging; therapy development; micro-supercapacitors

\section{Introduction}

Graphene is an appealing substance with its $\mathrm{sp}^{2}$-hybridized extended structure, which was reportedly generated by mechanical exfoliation for the first time in 2004 and since then, it has been attracting considerable attention with its two-dimensional (2D) zero band gap and is well-known for its excellent electrical conductivity [1-3]. Graphene quantum dots (GQDs), being zero dimensional nanomaterials, are basically derived from the 2D graphene with their extremely small structure. While GQDs have extraordinary attributes coming from the quantum world, they also embrace carbon-derived characteristics like chemical and physical stability. This is particularly important since carbon is considered as the source of life from many aspects. The bio-applicability along with the properties inherited from the carbonic structure enables various opportunities for biological applications to these tiny, nanoscale particles [4-7]. GQDs are semiconductor nanomaterials that belong to the carbon quantum dots family [8], they display superior photo stability against blinking and photo bleaching [9], possess low toxicity, high biocompatibility [10], and good colloidal stability [11]. Owing to quantum confinement and edge effects, GQDs are holding extraordinary properties and attracting extensive attention [12].

GQDs exhibit much stronger photoluminescence (PL) than graphene sheets (GSs) [13]. In addition, their stability in terms of PL is preserved by resistance against photo bleaching and blinking attributes [14]. Although the PL mechanism of GQDs has not been fully explained, the assumptions about the PL source are strongly based on quantum confinement and edge effects [15,16]. 
GQDs exhibit unique fluorescence properties due to quantum confinement effect and possess a non-zero bandgap in the structure. The properties of GQDs can be tuned by modifying the size and shape by affecting the characteristics of their final structure [17-20]. Also, they possess peroxidase-like catalytic activity, which favors them in label-free biosensing [21]. GQDs have loads of negatively charged carboxyl groups and conjugated $\pi-\pi$ bonds, which provide electrostatic properties for diverse applications [22], where the surface carboxyl groups bestow good water solubility to the GQDs [23]. The conjugation of other substances through the functional groups like carboxyl and hydroxyl groups found on the surface of GQDs can be facilitated [24]. The $\pi-\pi$ stacking that possessed by the GQDs structure is also a good mediator for various conjugations of numerous substances [25-27].

The possibility of cellular internalization offered by GQDs is reportedly mediated by several different pathways including energy-dependent as well as clathrin- and caveolae-mediated endocytosis. Precisely, this internalization ability could endow the possibility for GQDs to target the cells and cell-organelles like endoplasmic reticulum, Golgi apparatus, and nucleus [28-30]. In addition, GQDs can attach the DNA via intercalation and electrostatic paths for the applications in bioengineering [31]. It was also shown that carboxylic groups found on the N-GQDs surface can bind single stranded DNA for the purpose of fluorescent biosensing [32].

GQDs are unique, valuable, and play a prime role in many fields like biosensing [33,34], drug delivery [35], solar cells [36-38], micro-supercapacitors [39-41], photodynamic therapy [42], and optoelectronics [43]. Although they play a pivotal and most important function in the development of biosensors, in this paper, our chief motive is to highlight their applications in the field of bio-imaging [44], micro-supercapacitors [45], and therapy development [46], since we have broadly covered their significance and detailed biosensing applications in our recently published articles [33,34].

\subsection{Synthesis of GQDs}

GQDs are tiny carbon-sourced materials and can be synthesized by bottom-up or/and top-down methods via diverse chemical synthetic approaches [47]. The top-down approach is mainly based on the physical cutting of GSs, where the bottom-up approach is based on the chemical synthesis of GQDs in pieces from small molecular fragments while enabling the management of their morphological properties [48-50]. Nanolithography, electrochemical scissoring of GSs, chemical exfoliation, and hydrothermal as well as solvothermal cutting of GSs are the methods for cutting approaches to obtain GQDs [16]. Improved Hummer's method can be utilized extensively for the synthesis of GQDs, where the graphene oxide (GO) is the precursor of the quantum dot [51].

There are also some existing and well-established synthetic techniques offering advantages like smooth operation and low cost when synthesizing GQDs by direct carbonization of organic precursors such as amino acids, carbohydrates, ethylene diamine tetra-acetic acid (EDTA), di-thio-threitol (DTT), etc. While EDTA assisted N-GQDs, namely E-GQDs can be synthesized in a very short period of time, their characteristic analysis could reveal that these E-GQDs are the great candidates for opto-electronic and energy applications. In case of DTT yielded S-GQDs, 4-amino thio-phenol (ATP) could be a potent precursor for the nitrogen and phosphorous co-doped GQDs. It is worth noting that each precursor is treated at different temperatures in order to manufacture various heteroatom doped-GQDs [52].

Recently, Ji and coworkers developed a surface-assisted 'bottom-up' GQD synthesis method to successfully fabricate nanostructures smaller than $2 \mathrm{~nm}$ that enabled the quantum confinement studies [53]. A study showed that larger GQDs particles could be achieved by increasing the microwave heating time while utilizing the microwave-assisted hydrothermal method. The shorter lifetime was attributed to larger size of GQDs, resulted in lower quantum yield (QY) [54]. Likewise, the PL characteristics of GQDs was found to be pH-dependent [55]. Pan et al. developed a route of chemical reaction by proposing a simple hydrothermal approach to cut GSs into surface functionalized GQDs. Synthesized GQDs exhibited bright blue PL observed for the first time owing to the GSs and graphene nanoribbons (GNRs) because of their large lateral sizes [56]. 
Graphite is one of the most affordable and most readily attainable precursors for GQDs, and a study reported a facile method for synthesizing GQDs from graphite powders with a high yield and a chance of adjusting the emission of GQDs only by controlling system conditions during synthesis. Herein, the graphite was chemically oxidized at $40{ }^{\circ} \mathrm{C}$ to graphite oxide and the temperature of the system subsequently increased to $120^{\circ} \mathrm{C}$ and left to reflux in order to cut the graphite oxide into small dots by an improved Hummer's method that yielded crystalline GQDs in large scale [57]. Ye and coworkers achieved synthesis of GQDs from coal by proposing crystalline coal's sp ${ }^{2}$ carbon structure as quantum dot source. Three different types of coal were used to derive GQDs; resultantly they have demonstrated different colors of fluorescence. Additionally, GQDs demonstrated solubility in water and held promising features for several bioengineering and electronics applications [55]. Another study involving the use of coal as the source of GQDs highlighted the antioxidant property of GQDs owing to their biocompatibility. Here, GQDs with oxidation sites were preferred for the antioxidant feature and these antioxidant GQDs were found to not possess fluorescence property, due to the modulation of reduction potential [58]. It is plausible to say that there are lots of GQD synthesizing methods which can be changed, modified, and improved with different approaches such as one-step solvothermal method [26], direct pyrolysis of citric acid [59], and hydrothermal fragmentation [60]. The important thing to pay attention is, each particular application demands a specific synthetic approach according to its necessity. Table 1 enlists various methods for the synthesis of GQDs using distinct sources with their reported sizes and corresponding QY. 
Table 1. Various approaches for synthesizing GQDs with their respective size ranges and QY.

\begin{tabular}{|c|c|c|c|c|c|}
\hline Modification & Source/Precursor & Synthesis Method & Size & QY & Reference \\
\hline A-GQDs & Graphite and adenine precursors & Two-step microwave-assisted method & $3-5 \mathrm{~nm}$ & $21.63 \%$ & [61] \\
\hline Hg-PEHA-GQD-DPA & Citric acid & Two-step continuous thermal pyrolysis & $3.16 \mathrm{~nm}$ & $90.91 \%$ & {$[62]$} \\
\hline RF-GQDs & Graphite in $\mathrm{K}_{2} \mathrm{~S}_{2} \mathrm{O}_{8}$ solution & Electrochemical exfoliation & $3 \mathrm{~nm}$ & $1.8 \%$ & {$[63]$} \\
\hline B-GQDs & $\begin{array}{l}\text { 4-vinylphenylboronic acid } \\
\text { and boric acid }\end{array}$ & - & $5.8 \mathrm{~nm}$ & $11.2 \%$ & [23] \\
\hline$(\mathrm{GQD} / \mathrm{DBM})_{3}$ EuPhen/GQD & Graphite rod & Electrochemical exfoliation & $5.5 \pm 0.4 \mathrm{~nm}$ & $15.5 \%$ & [64] \\
\hline sGQDs & $\begin{array}{c}\text { Ethanolic extract of grape seed } \\
\text { extract powder }\end{array}$ & One-pot microwave-assisted synthesis & $\sim 50-60 \mathrm{~nm}$ & $31.79 \%$ & {$[30]$} \\
\hline DOX-GQD-RGD & Thermally exfoliated graphite oxide & Refluxing with concentrated nitric acid & $3.7 \mathrm{~nm}$ & - & [65] \\
\hline GQDs & Trisodium citrate & Pyrolytic carbonization route & $1.3 \pm 0.5 \mathrm{~nm}$ & $3.6 \%$ & [9] \\
\hline mGQDs & Mango leaves & $\begin{array}{l}\text { One-pot microwave-assisted } \\
\text { green-synthesis route }\end{array}$ & $2-8 \mathrm{~nm}$ & - & {$[66]$} \\
\hline HD-GQDs, LD-GQDs & Acetylene black, nano-graphite & $\begin{array}{l}\text { Ultrasonic-assisted liquid-phase } \\
\text { exfoliation technique }\end{array}$ & $2-6 \mathrm{~nm}, 2-9 \mathrm{~nm}$ & $1.8 \%, 2.4 \%$ & [67] \\
\hline GQDs & Graphite rod & Electrochemical exfoliation method & $1.5-5.5 \mathrm{~nm}$ & - & {$[68]$} \\
\hline F-GQDs & Fluorinated graphite & Oxidative cutting method & $2.1 \mathrm{~nm}$ & $13.72 \%$ & [69] \\
\hline GQDs & Pyrene precursor & $\begin{array}{l}\text { Wet chemistry treatment of commercially } \\
\text { available polycyclic aromatic hydrocarbon }\end{array}$ & $5-10 \mathrm{~nm}$ & $11.7 \%$ & {$[70]$} \\
\hline
\end{tabular}

Abbreviations: A-GQDs: Adenine-modified GQDs; B-GQDs: Boron-modified GQDs; DBM: Dibenzoylmethane; DOX: Doxorubicin; DPA: D-penicillamine; Eu: Europium; F-GQDs:

Fluorinated GQDs; HD-GQDs: High defect GQDs; Hg: Mercury; $\mathrm{K}_{2} \mathrm{~S}_{2} \mathrm{O}_{8}$ : Potassium persulfate; LD-GQDs: Low defect GQDs; m-GQDs: Magnifera indica derived GQDs; PEHA:

Pentaethylenehexamine; Phen: Phenanthroline; RF-GQDs: Red fluorescent GQDs; RGD: Arginine-glycine-aspartate; s-GQDs: Self-assembled GQDs; QY: Quantum yield. 


\subsection{Biofunctionalization/Conjugation of GQDs}

GQDs are being predominantly fashionable materials with their bio-applicable properties including eco-friendly nature [71]. They have been shown to be undeniably valuable throughout the research reported in recent decades. However, when functionalized in several ways, their properties and characteristics showed an improved trend line by encouraging fine-tuning and target-oriented applications.

The functionalization of GQDs prevents the aggregation caused by powerful $\pi-\pi$ interactions among the GQDs [53] and cytotoxicity created by GQDs is confirmed to be dosage-dependent [72]. In a study based on the GQDs' cytotoxicity, the mitigation of toxicity levels was developed on the hypothesis of whether the damage stemmed from the small sizes of GQDs or from their ability to create reactive oxygen species (ROS) intracellularly. Although the fewer amounts of GQDs do not necessarily create intracellular cytotoxicity, higher levels like more than $1 \mathrm{mg} \mathrm{mL}^{-1}$ result in cell deaths. Hence, the PEGylation of GQDs was employed to lessen the cytotoxicity that was thought to be a consequence of the decreased generation of ROS; thus the higher levels of GQDs utilization inside a cellular compartment was justified up to $8 \mathrm{mg} \mathrm{mL}^{-1}$ with $50 \%$ viability [73]. Another cytotoxicity study investigated the modifications of GQDs, and their contribution to the cell viability or lethality showed that even though GQDs hold varying groups like $-\mathrm{NH}_{2},-\mathrm{COOH}$, and $-\mathrm{CO}-\mathrm{N}\left(\mathrm{CH}_{3}\right)_{2}$ on the structure, the low cytotoxicity phenomenon was preserved with no distinct changes proving the biocompatibility of the modified GQDs even at the concentration up to $200 \mu \mathrm{g} \mathrm{mL} \mathrm{m}^{-1}$. Results were assessed by the MTT assays performed on $A_{549}$ lung carcinoma cells and $C_{6}$ human neural glioma cells [74]. Another study investigated the contribution of size and concentration of the GQDs into cytotoxicity utilizing molecular dynamics simulations to reveal the structure and pristine GQDs' translating mechanism at the molecular level, which showed that the smaller GQDs could permeate into the lipid bilayer, while bigger GQDs needed more time [75]. Moreover, it was also reported that the high concentrations of GQDs induced changes in the structural properties and diffusion characteristics of the lipid bilayer, and they may affect the cell signal transduction, revealing the fact that the cytotoxicity of GQDs with smaller size is low, which can be favorable for the bio-applications [75].

An early 2019 study, investigating the functionalization effects of GQDs on inducing cytotoxicity and autophagy of aminated (a-GQDs), carboxylated (c-GQDs), and hydroxylated GQDs (h-GQDs), made a consensus on the ability of autophagy and apoptosis. The h-GQDs showed distinctly more cytotoxicity comparing to the remaining two, whereas the c-GQDs was the most cyto-compatible among them, and was thus referred by the author as the "safest modification on GQDs" [76]. This is a good example that highlights the importance as well as the significance of synthesis and modifications of GQDs, which can be adjusted according to the aim of their respective application.

GQD-incorporated thin film composite membranes were composed to be utilized in forward osmosis (FO) desalination. A 2D sheet with $2.19 \mathrm{~nm}$ morphology of GQDs could make covalent bonding with polyethylenimine by forming stable GQD-incorporated membranes. In this scenario, GQDs could promote the water permeability and enhance the water-flux [77]. As far as the antibacterial properties of the "GQDs enhanced $\mathrm{TiO}_{2} / \mathrm{Sb}_{2} \mathrm{~S}_{3}$ nanocomposite" against Escherichia coli (E. coli) and Staphylococcus aureus is concerned, the existence of GQDs in the nanocomposite could result in the generation of more electron and hole pairs, meaning more powerful antibacterial activity could be achieved with minimum inhibitory concentrations of 0.03 and 0.1 , respectively [78].

As indicated previously, quantum dots (QDs) are small yet valuable formations. This smallness of the quantum dots gives them the unique optical properties like absorption and emission, thus resulting in better outshine than regular fluorescent compound and it is undeniable that GQDs become prominent due to their non-toxicity property, separating them from the other semiconductor QDs. Accordingly, this makes it easier and more reasonable to utilize GQDs in biological applications $[79,80]$.

Since the first synthesis of chiral GQDs from Vázquez-Nakagawa's group, the modification of GQDs has gained a new aspect. The synthesis of chiral GQDs was performed for the first time with the esterification with enantiomerically pure alcohol of $(R)$ or $(S)-2$-phenyl-1-propanol where the chirality 
could be transferred to pyrene [81]. In addition, the utilization of GQDs on chiral separation was envisioned as a chromatographic separation agent by $\mathrm{Wu}$ et al. and further proved that the GQDs are appropriate agents for enantio-separation according to the comparison of the column efficiencies of $\beta$-cyclodextrin ( $\beta-C D)$ and cellulose silica composites both with and without GQDs. This study is also a good operation of molecular modeling in terms of revealing the dynamics between molecules and bringing clarification to why GQDs magnify the efficiency. According to the authors' explanation, "GQDs provide extra interactions such as hydrophobic, hydrogen bond, and $\pi-\pi$ interaction", which makes this conjugation of GQDs plausible in the first place [82]. Moreover, the conjugation was also confirmed and employed by a sensor system that was designed to enantio-recognize of tryptophan isomers [83]. Additionally, it is possible to synthesize GQDs in combination with heteroatoms like nitrogen (N) [31,84,85], sulfur (S) [86-88], boron (B) [89], and oxygen (O) [90] which in turn, these dopings may enhance the capabilities of GQDs in varying manners. For instance, N-doped GQDs synthesized by a hydrothermal reaction could show high antioxidant property as compared to the conventional antioxidant agent utilized in food safety [31]. These N-GQDs hold an outstanding photocatalytic structural performance with considerably high QY [91]. A recently published study revealed loads of beneficial data about GQDs and their conjugation with hetero atoms like N and S. The N,S-GQDs, synthesized from citric acid and L-cysteine precursors can be conjugated with streptomycin antibiotic to develop drug conjugated QD for the improvement of drug efficiency, intracellular imaging and biocompatibility investigations. The presence of heteroatoms in GQD strengthens several prospects to promote the PL as well. The proposed N,S-GQD system was enriched by hydrophilic functional groups like $-\mathrm{COOH},-\mathrm{OH}$, and $-\mathrm{NH}_{2}$ to provide solubility and drug conjugation [79]. In large scale productions of GQDs, their functionalization by sulfonation could provide re-dispersion in water and consistent fluorescence, and these sulfonated GQDs can be beneficial for intracellular Golgi imaging [28]. Figure 1 represents the summary of bio-conjugation of GQDs.

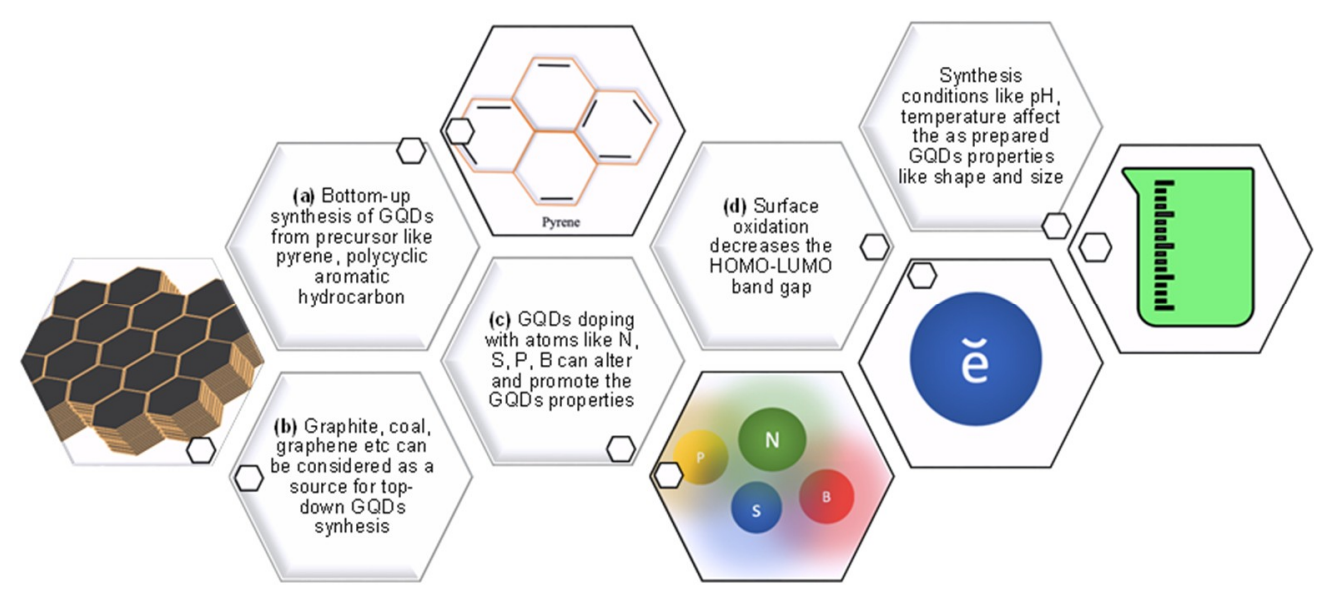

Figure 1. (a) Pyrene and polycyclic aromatic hydrocarbon along with other substances can be the precursor required for bottom-up GQDs synthesis [70,92]. (b) Several substances that can be the carbon source for top-down GQDs synthesis. (c) Doping graphene with heteroatoms, such as S, N, B, and P, can expertly manage a tunable gap in graphene's energy spectrum and thus produce new phenomena, alter and improve properties of the dot $[85,86,93,94]$. (d) The size and the shape of the GQDs alter the energy levels of the highest occupied molecular orbitals (HOMO) and the lowest unoccupied molecular orbitals (LUMO) in correlation with the change of absorption spectra where the PL of GQDs are related to the passage from LUMO to HOMO levels. The band gap between HOMO-LUMO can also be decreased with the increase in surface oxidation of GQDs [95-97].

It could be suggested that GQDs can be a proper photodynamic therapy (PDT) agent due to their ability to create photosensitized oxygen. The study proposed by Jovanovic and the group revealed the vital effects of functionalization of GQDs when it comes to PDT applications. Introducing urea and 
thiourea, the N, S co-doped GQDs were synthesized as a better singlet oxygen generator compared to sole GQDs and accordingly, GQDs with urea were defined to be a good PDT agent. The modification with nitrogen could enhance the capability of GQDs by means of crystallinity and mediate more photo-excited singlet oxygen generation, resulting N, S- doped GQDs to be anti-oxidative [98].

\subsection{Impact of Toxicity Potential and Biocompatibility of GQDs}

The cyto-compatibility of GQDs results in tremendous biological applications and is already desirable for many cases. Yet, the probable cytotoxicity effects of GQDs on living cells should be considered concerning the biosafety [99]. Moreover, currently the researchers are investigating the best possible treatment and alternative approaches when it comes to human life; however, utilizing GQDs is a two-way road that should be evaluated carefully [100].

It has been well summarized by Zhang et al. that GQDs with small sizes and concentrations in the range of micrograms and milligrams were non-cytotoxic to mice and human cell lines. However, it should also be emphasized that several studies reported toxic effect of GQDs [101]. Wang et al. studied the cytotoxicity mechanism of N-GQDs and GO for the first time in 2014. Since the cytotoxicity was raised by the nonspecific adhesion of nano-sized particle to the cell membrane, the interaction between carbonic structures and red blood cells (RBCs) was evaluated. Accordingly, the N-GQDs were decided to be cytotoxic to the RBCs even they did not cause more serious effects than the GO [102]. Also, it was emphasized that the route of interaction between the living compartment and GQDs should be thoroughly investigated in order to obtain comprehensive information regarding the effect mechanism. On the other hand, PDT applications of GQDs are still pending for the detailed results regarding the cytotoxicity [103]. Another important aspect to toxicity of the GQDs is the excretion route of the GQDs after their application. As shown by Lee et al., GQDs were excreted from mice via renal pathway subsequent to their degradation by several enzymes like horseradish peroxidase (HRP) [104]. In addition, the degradation of GQDs by human myeloperoxidase and eosinophil peroxidase enzymes was also proven [105]. In order to decrease the toxicity caused by GQDs, PEGylation was suggested as a valid solution [73]. Another study conducted with the principle of PEGylation showed that the PEGylation may indeed lower the cytotoxicity since the GQDs themselves did not cause any remarkable cell death even at the concentrations of $160 \mu \mathrm{g} \mathrm{mL}{ }^{-1}$ conducted in vitro with HeLa cells. In the same study, the comparison of GO-PEG and GQD-PEG was conducted in vivo which resulted in remarkable biocompatibility of GQD-PEG conjugation whereas three mice could not survive without any sign after the GO-PEG injection. The desirable biocompatibility was related with the small sizes and ease of clearance from their body and high oxygen content [106]. In a very recent study, it was demonstrated that GQDs can alter one gene's expression on $\mathrm{CD}^{34+}$ hematopoietic stem cells after 36 hours of incubation, which is a negligible number within 20,800 genes [107].

As depicted in Figure 2, graphene also influences biologically at the cellular, subcellular, protein as well as genetic levels. The toxicity of graphene is based on its uptake in various particular organs as well as on its physical and chemical interference. Accumulation of graphene in such organs affects cellular performance. Their impeachment, dispensation, and excretion after entering in a cellular environment retrieve the information about their cyto-toxicity [108]. Mitochondria imaging has been achieved with several methods formerly, like making GQDs accumulate mitochondrial and lysosomal site by simple modification of aptamer AS1411 in order to label tumor cells. Yet the exact uptake mechanism of AS1411-GQDs remained unknown and was assumed to be similar as AS1411 [109]. Later on, when Fan et al. studied the GQDs-TPP (GQDs-phenyl bromide phosphine) as a targeted mitochondria imaging agent, they expected the lipophilic TPP to cumulate in the mitochondria for targeted imaging. Expectedly, nuclear and mitochondrial imaging was performed without any cytotoxic side effects [110]. 


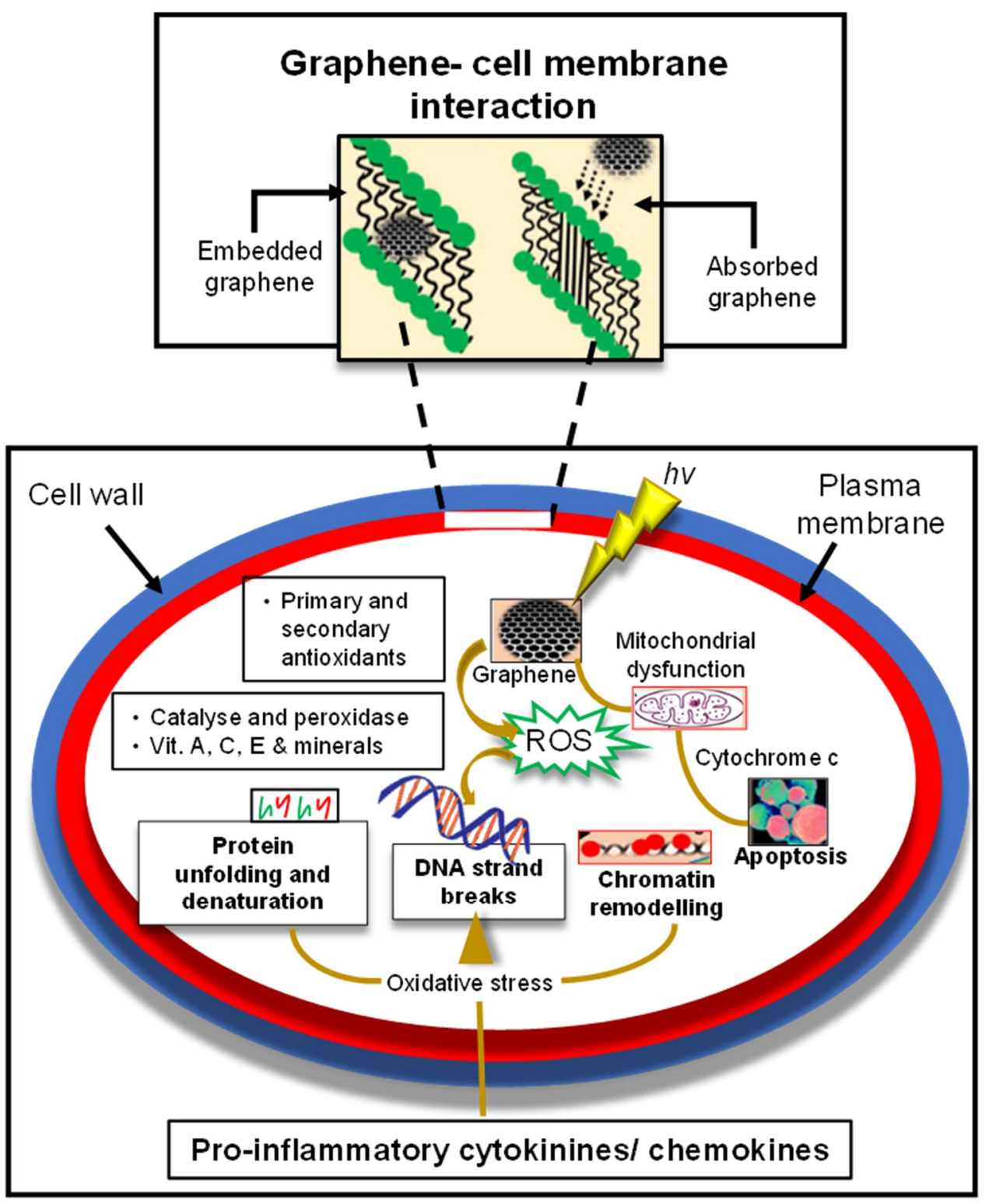

Figure 2. Schematic representation of the effective mechanisms by which ROS are linked with the toxicity of graphene at a cellular level. Adapted from [108].

It is an undeniable fact that the GQDs are being promising in numerous applications nowadays as aforementioned; however, it is an obligation to evaluate the adverse effects of GQDs in order to provide biosafety when translated into the clinical applications. Surface enhanced infrared absorption spectroscopy (SEIRA) has been very useful tool to assess the relationship between GQDs and their environment in the field of toxicology [102]. Table 2 outlines various forms of GQDs that are responsible for cytotoxicity. 
Table 2. GQDs and their cytotoxic effects.

\begin{tabular}{|c|c|c|c|c|}
\hline GQD-Type & Cytotoxicity & Media & Notes & References \\
\hline GQDs & $\begin{array}{l}\text { GQDs have minimal dark } \\
\text { toxicity }\end{array}$ & In vivo toxicity in rats & $\begin{array}{l}\text { Some minor changes were } \\
\text { particularly noted in the } \\
\text { liver and lungs at the } 10 \text { and } \\
15 \mathrm{mg} / \mathrm{kg} \text { doses of GQDs }\end{array}$ & [103] \\
\hline $\begin{array}{l}\text { Carboxylated } \\
\text { GQD }\end{array}$ & $\begin{array}{l}\text { No acute cytotoxicity between } \\
\text { the range of } 5 \text { and } 10 \mathrm{mg} / \mathrm{kg}\end{array}$ & $\begin{array}{l}\text { Liver, spleen, kidney, } \\
\text { and tumor/In vivo and } \\
\text { in vitro }\end{array}$ & $\begin{array}{l}\text { Accumulation in mice liver, } \\
\text { spleen, kidney, and tumor at } \\
24 \mathrm{~h} \text { after intravenous } \\
\text { injection of GQDs }\end{array}$ & [111] \\
\hline GQDs & $\begin{array}{c}\text { No severe toxicity in mice } \\
\text { with } 300 \text { micrograms of GQDs } \\
\text { (per head, } 15 \mathrm{mg} / \mathrm{kg})\end{array}$ & $\begin{array}{l}\text { Intraperitoneal } \\
\text { infusion to mice }\end{array}$ & $\begin{array}{l}\text { GQDs could be excreted out } \\
\text { of the body }\end{array}$ & [104] \\
\hline GQDs & Low toxicity & $\begin{array}{c}\text { Blood derived } \mathrm{CD}^{34+} \\
\text { cells from } \\
\text { leukapheresis }\end{array}$ & $\begin{array}{l}\text { SEPW1 is downregulated } \\
\text { with a fold change of }-5\end{array}$ & [107] \\
\hline GQDs & Very low cytotoxicity & $\begin{array}{l}\text { B16F10 cells and } \\
\text { MCF-7 cells }\end{array}$ & & [68] \\
\hline GQDs & $\begin{array}{c}\text { Low cytotoxicity to } \\
0-400 \mu \mathrm{g} \mathrm{mL}^{-1} \text { GQDs for } 24 \mathrm{~h}\end{array}$ & $\mathrm{HeLa}$ & $\begin{array}{c}\text { More than } 80 \% \text { cell } \\
\text { survival rate }\end{array}$ & [9] \\
\hline GQDs & No overt acute toxicity & Lung tissues of rats & $\begin{array}{c}\text { In high dose group alveolar } \\
\text { septa thickening during } \\
\text { inflammation }\end{array}$ & [100] \\
\hline
\end{tabular}

\section{Bio-Imaging Applications of GQDs}

Bio-imaging is one of the most significant areas, where GQDs offer several benefits in an auspicious way [92,112]. In definition, bio-imaging is a way to see, observe, and detect the desired molecules or tissues in the body without performing any invasive application [113], which enables more comprehensive understanding of the biological pathways in the body [114]. When Wilhelm Roentgen could capture the first X-ray image in 1896 [115], since then, a new door has been opened for prospective bio-imaging applications to detect and monitor various diseases and symptoms like bone fractures [116], carcinoma [117], Parkinson's disease [118], tumor imaging [119], etc.

GQDs are convenient and desirable agents in bio-imaging due to their admirable tunable PL characteristics, chemical inertness, high photo-stability, and excellent biocompatibility properties [64]. Moreover, GQDs hold superior properties compared to their counterparts of other carbon-derived materials [30] like noteworthy resistance to photo-bleaching that facilitates good bio-imaging purposes [110]. As a case in point, it was revealed that due to crystalline structure, GQDs are superior to carbon nanodots (CNDs) when irradiated with a Xenon lamp in terms of their bleaching activity and stability [97]. GQDs were proven to be stable particles during the imaging process without spoiling any results [28], and their fluorescence imaging with near-infrared (NIR) spectra is often encountered in the studies $[66,120,121]$.

There are several other methods rather than solely utilizing GQDs in bio-imaging studies like organic dyes. However, the poor photostability, low QY, susceptibility to photobleaching, and unavailability for multicolor imaging characteristics are offered with these dyes [122]. On the side, QDs have been used for a while as imaging tools and are very well integrated into bio-imaging systems since they have overcome the challenges of conventional dying methods; however, later on, their toxicity became an issue for biological applications. In spite of toxicity caused by other semiconductor QDs, GQDs are justified for non- or minimum-toxicity features in biological tissues [74,75].

On the other hand, these GQDs could show elevated levels of illumination and photo-stability, along with their size-tunable properties [123,124]. Notably, the first demonstration of GQDs smaller than $10 \mathrm{~nm}$ in size could generate 'bright-blue-PL', different than GSs and graphene nanoribbons, started a new stage. This accelerated optoelectronic and labeling studies, as well as prospective GQD-utilized-bio-imaging applications. It is crucial to notice that strong luminescent emission of GQDs can be attributed to the dense, free zigzag edges found in the tiny structure stemming from 
$<10 \mathrm{~nm}$ size. Also, it was shown that PL emission was highly dependent on the $\mathrm{pH}$ of medium; i.e., alkaline mediums could give the strong PL, whereas acidic media could not support it, suggesting that PL behavior can be reversed by altering the $\mathrm{pH}$ of the medium [56].

Plausibly, new methods that use GQDs for bio-imaging applications were quickly developed, owing to the desirable features of GQDs in terms of bio-applicability and non-toxicity compared to inorganic QDs [64,111,125]. As one of the first studies of GQDs for bio-imaging, Zhu et al. proposed a one-step solvothermal method for highly green-PL GQDs with an $11.4 \%$ QY, which emphasized that the GQDs can be employed as bio-labeling agents due to their bio-applicable characteristics [126]. With the time, the QY and conjugations of GQDs with other materials enabled better results in terms of their efficiency and utility. GQDs' surface-modifications were shown to affect the PL [127], whereas photo-chemical reduction method was suggested for the increasing QY and elevated cell uptakes of GQDs [128]. GQDs' surface-functionalization with small organic molecules proved to be an effective strategy for PL tunability through altering the band gaps, and decreasing the cellular toxicity [129]. Varied color emissions of GQDs were obtained with different synthetic approaches for bio-imaging aims. For instance, N-GQDs with blue luminescence were prepared by hydrothermal treatment of GO. Herein, 24.6\% QY and biocompatibility of N-GQDs were high enough to illuminate HeLa cells, meanwhile having the blue-shift property with the increasing $\mathrm{pH}$ and temperature dependency influence the PL intensity [130]. Green luminescent GQDs can be synthesized by a facile synthesis method in large-scale from graphite powder for imaging human hepatic cancer cells [131]. Later on, water-soluble, uniform-sized GQDs with red fluorescence (RF-GQDs) demonstrated a high bio-imaging applicability, through their dominant red color as a robust biological marker for stem cells [63].

It was shown that the green synthesis of GQDs could overcome the cytotoxicity due to their biocompatibility as well as their excellent sized-tuned emission features [125]. A study that employed mango leaves as the source for GQDs showed total cellular uptake and cell viability, even at high concentrations, for $24 \mathrm{~h}$ of GQD treatment while showing NIR emissions between $650-750 \mathrm{~nm}$. This NIR excitation-independent fluorescence emission could satisfy the need for far penetration into tissues required for in vivo administrations [66]. In the course of cytotoxicity, recently, Yan and coworkers proposed a highly biocompatible GQDs (HGQDs) synthesis method by only employing glucose in the absence of any acids or oxidizers. HGQDs were synthesized via hydrothermal one-pot method by autoclaving the glucose solution at $200^{\circ} \mathrm{C}$ for $10 \mathrm{~h}$. In contrast to conventionally synthesized GQDs (CGQDs), HGQDs possessed diminished levels of apoptosis with almost $60 \%$ reduced cytotoxicity and $2.24 \%$ QY, exhibiting superior cyto-compatibility compared to the conventionally synthesized GQDs owing to glucose precursors. The as-prepared HGQDs were shown to have a similar structure to glucose, which in turn could enhance the cellular uptake of these small dots due to such similarity. HGQDs were accumulated in the liver, kidney, and brain of mice, revealed by ex vivo tests. Moreover, it was examined that cancerous cell viability was increased by sugar based HGQDs. Cancer cell imaging showed that CGQDs could damage the cancerous cells when interacted, whereas the HGQDs could bestow better cytocompatibility for bio-imaging. Likewise, bacterial imaging studies supported the earlier results of CGQDs' shape-destructive characteristics compared to HGQDs. When ex vivo imaging was performed with the isolated organs of mice, which were already treated with HGQDs for 20 days, the liver, kidney, and brain confirmed to possess HGQDs (Figure 2). Their accumulation particularly in the brain indicated that the as-prepared GQDs can pass through the blood-brain barrier. This approach may facilitate the prospective brain-related studies for GQDs-imaging [10].

In a 2017 study, as a novel application, Chen and coworkers could successfully functionalize GQDs with sugar moieties, referred to "sweet GQDs" that were used for real-time monitoring of specifically labeled carbohydrate receptors to pursue their real-time dynamics. The synthesized GQDs had almost QY of $31 \%$ and small sizes of $5.4 \mathrm{~nm}$. Consequently, since the investigation of some overexpressed receptors in tumors could help the identification of certain cancerous cells, the galactose tagged GQDs (Gal-GQDs) could specifically interact with overexpressed galactose receptors in the liver and fluorescently lighten them up. Likewise, mannose receptors were overexpressed in human 
breast cancer cells, and Man-GQDs could selectively identify mannose receptors found in the several body parts [92].

Magnetic resonance imaging (MRI) is one of the numerous imaging tools that exist to allow the clinical diagnosis along with other techniques like positron-emission tomography (PET), computed tomography (CT), fluorescent and photoacoustic imaging, as well as medical optical imaging [132,133]. As one of the most advantageous imaging methods, with its gadolinium oxide $\left(\mathrm{Gd}_{2} \mathrm{O}_{3}\right) \mathrm{T} 1$ (positive) contrast agents, MRI technique can be coupled with the two-photon fluorescence imaging (TPFI) GQDs. Wang and coworkers offered an excellent and MR suitable contrast agent, i.e., GQD-conjugated $\mathrm{Gd}_{2} \mathrm{O}_{3}$. Owing to the abundant edge functional groups on GQD layers, colloidal stability and biocompatibility of nanocomposites in water, it was reported that $\mathrm{Gd}_{2} \mathrm{O}_{3} / \mathrm{GQD}$ could exhibit tremendous optical properties, where the MR relaxivity $\left(15.995 \mathrm{mM}^{-1} \mathrm{~s}^{-1}\right)$ proved that $\mathrm{Gd}_{2} \mathrm{O}_{3} / \mathrm{GQD}$ could serve as an MR T1 contrast agent. Moreover, both one-photon and two-photon diagnostics were possible with the proposed agent [134].

The importance of the TPFI is stemmed from the fact that it can perform non-invasive tissue penetration and can minimize the cytotoxicity when interacted with tissues [135-137], which make them advantageous for bio-imaging. The TPFI enables more extended detection time and reduced photo-damage for the tissue [138]. The metal-free boron-doped magnetic GQDs (B-GODs) were shown to display sustainable behaviors convenient for TPFI and near infrared (NIR) imaging contrast agent. Wang and coworkers proposed B-GQDs as a safe T1 contrast agent for MRI, due to the ferromagnetic property of metal-free (MF) graphene since Gd-based contrast agents could model some safety concerns. Henceforth, the suggested $5 \mathrm{~nm}$ sized B-GQDs demonstrated a paramagnetic property without any metal employment, enabling the potential service as a contrast agent for T1 MRI [23].

N-GQDs were demonstrated as a TPFI probe on the intra-lipid mock tissue and resulted a good bio-imaging quality. Additional to the aforementioned properties of GQDs, a lack of thermal damage caused by the heat of irradiation characteristics of the proposed GQDs showed deep tissue penetration up to $1800 \mu \mathrm{m}$ (Figure 3) [139]. Moreover, in a study that employed both the bio-imaging and biosensing experiments executed with the large-scale-synthesized GQDs were efficiently internalized by the MCF-7 cells and generated a strong bio-imaging capability. As the sensing unit, the existence of $\mathrm{Fe}^{3+}$ ions in the medium quenched the fluorescence (Figure 4). These polycyclic aromatic hydrocarbon derived GQDs measuring 5-10 nm were shown to be an excellent bio-imaging probes with features such as solubility, PL, low toxicity, and stability [70]. Another study related to $\mathrm{Fe}^{3+}$ sensing with GQDs inferred that rhodamine B functionalized GQDs (RBD-GQDs) pair can indeed sensitively detect $\mathrm{Fe}^{3+}$. Here, Guo et al. showed that $\mathrm{Fe}^{3+}$ detection resulted with a peak at $559 \mathrm{~nm}$. The authors claimed that a ring opening phenomenon was occurred via $\mathrm{Fe}^{3+}$ in the RDG structure. However, in contrast to the previous results where the $\mathrm{Fe}^{3+}$ detection led to the decreased PL, the results of this study showed that as the $\mathrm{Fe}^{3+}$ increases, the fluorescence intensity increases where the saturation point is $22.5 \mu \mathrm{M}$ of $\mathrm{Fe}^{3+}$ ( $\mathrm{pH}$ 7.0) [140]. Another study related to this specific $\mathrm{Fe}^{3+}$ detection in an acidic medium demonstrated that at $\mathrm{pH} 3.5$ without any special treatment, GQDs can specifically detect $\mathrm{Fe}^{3+}$, even in the co-existence of other ions. However, the increasing $\mathrm{pH}$ value showed the interference from other ions and selectivity for $\mathrm{Fe}^{3+}$, which was quite low at $\mathrm{pH}$ 1.4. Moreover, this study showed similar results in terms of quenching performed by $\mathrm{Fe}^{3+}$ [141]. 


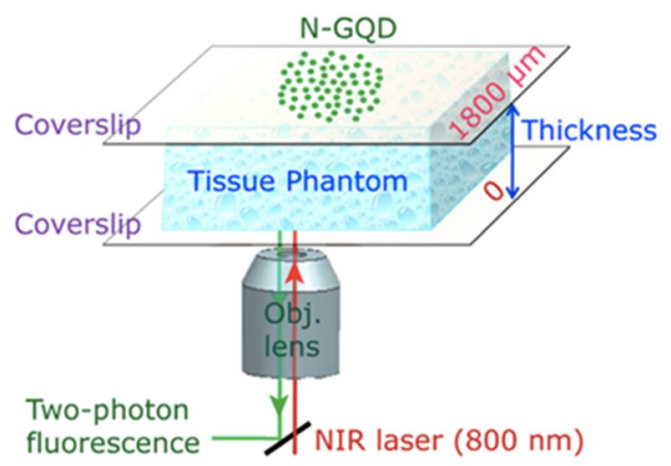

Figure 3. Schematic representation of the set-up used for TPFI of N-GQDs in tissue phantom with different thickness. TPFI is known for deep penetration into tissue with mitigated photo-damage during application. TPFI of N-GQD was analyzed using a NIR femtosecond laser as excitation and implemented for tissue imaging up to the penetration depth of $1800 \mu \mathrm{m}$. With negligible photo-thermal effects of N-GQDs, it was possible to use N-GQDs in TPFI on living cells with strong fluorescence [139].

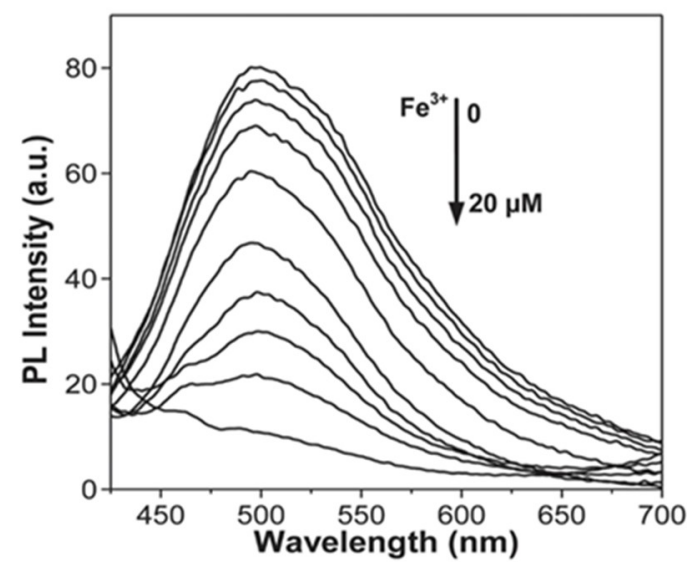

Figure 4. PL intensity changes due to the $\mathrm{Fe}^{3+}$ application on the quenching mechanism $\left(\lambda_{\mathrm{ex}}=400\right.$ $\mathrm{nm}) . \mathrm{Fe}^{3+}$ ions are indispensable, and it was hypothesized that GQDs can be a detector of $\mathrm{Fe}^{3+}$ since they have phenolic hydroxyl groups. These results indicate that luminescent GQDs can also be used to detect $\mathrm{Fe}^{3+}[70]$.

A $\mathrm{Cr}(\mathrm{VI})$ biosensing and bio-imaging system were submitted on the MCF-7 cells as well. The biosensor system was adjusted for the detection of $\mathrm{Cr}(\mathrm{VI})$ even under running water, with a limit of detection (LOD) of $91 \mathrm{nM}$. The N-GQDs were synthesized by a one-step hydrothermal method with a 64.2\% QY. N-GQDs were proven to be an exceptional in terms of their stability. As a fluorescent probe, the quenched N-GQDs were recovered by adding $\mathrm{Na}_{2} \mathrm{~S}_{2} \mathrm{O}_{5}$ and $\mathrm{FeSO}_{4}$. The imaging studies performed on MCF-7 cells showed that N-GQDs can be utilized for further bio-imaging activities since these particles were internalized via endocytosis and could produce a blue-PL under $405 \mathrm{~nm}$ excitation light [142]. Likewise, in a recent study, a biomass-derived N-GQDs were hydrothermally synthesized and employed as fluorescent inks. Herein, the final structure of N-GQDs could exhibit the blue, green, and yellow emission under 472, 509, and $565 \mathrm{~nm}$, respectively. The bio-imaging part was demonstrated as a multicolor PL system, where it had a $29 \%$ of QY that resulted due to their desirable bio-applicability properties. Having exhibited higher stability under irradiation, the resistance against photobleaching of N-GQDs was proved and shown to be non-toxic for the fibroblast cells (Figure 5). On the other hand, the prepared N-GQDs were illustrated to be greatly quenched by $\mathrm{Ag}^{+}$ions, indicating the biosensing activity against this particular ion. In this case, the $\mathrm{Ag}^{+}$ion detection was enabled via N-GQDs with an LOD of $1.2 \mathrm{nM}$ via 'turn-off' principle. The quantification of $\mathrm{Ag}^{+}$ions in water samples is significant for environmental analysis, since excess $\mathrm{Ag}^{+}$ions may cause toxic effect in skeletal system and liver as indicated by the World Health Organization (WHO) [143]. Due to this reason, it was shown in 
sensing experiments that N-GQDs were extremely sensitive for the $\mathrm{Ag}^{+}$ions compared to the other metal ions. In this study, the PL intensity was in correlation with the $\mathrm{pH}$ levels of the medium where the optimum quenching value was obtained at $\mathrm{pH} 7.0$ while the different wavelengths generated multicolor emissions to enable cell imaging. Moreover, when N-GQDs were incubated with fibroblast cells, it was observed that there was almost no toxicity in the system [143].

a)
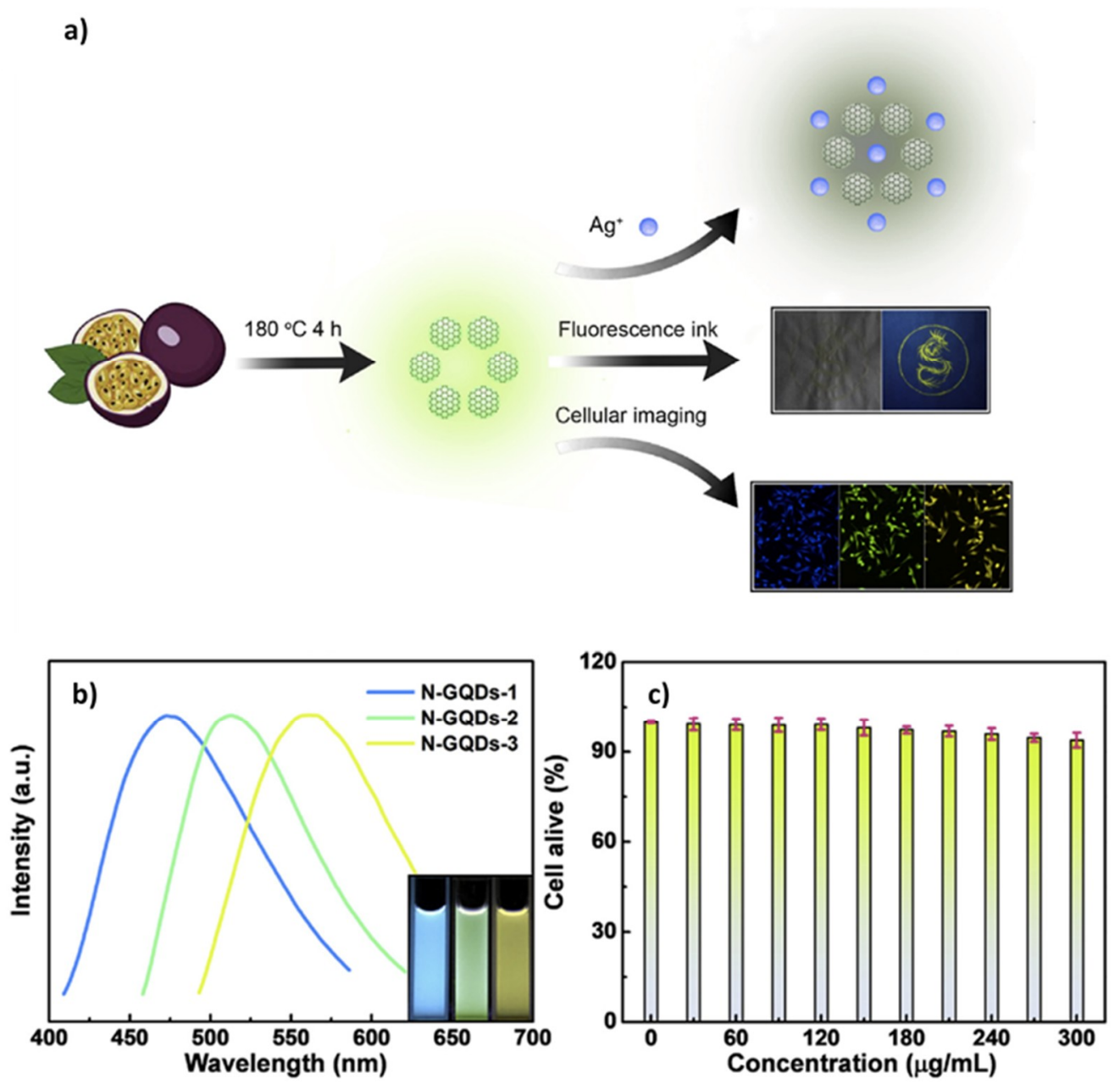

Figure 5. (a) Representation of the synthesis of N-GQDs from Passiflora edulia Sims, followed by the biosensing, ink, and bio-imaging applications. (b) The mechanism for the multicolor emissions of the N-GQDs was performed under different wavelengths. Blue, green, and yellow emissions were obtained under 472, 509, and $565 \mathrm{~nm}$, respectively. (c) The correlation between the increasing amounts of N-GQDs and fibroblast cell viability [143].

Another N-doping study conducted with GQDs was recently published on the subject of controllable doping of GQDs [82]. The doping was performed with dimethylformamide via UV radiation at room temperature, where the doping concentration was changed upon the reaction time. Hence, as a result, GQDs were confirmed to have different QY based on their varying reaction times and doping concentration. The increasing doping of GQDs elevated the QY and provided a blue shift. The emission wavelength was shown to be tunable from 566 to $463 \mathrm{~nm}$ with the increase in reaction time. These N-GQDs were also nontoxic in vitro and produced great PL inside the fibroblast cells. Like the former studies with no obvious and significant cell death, the biocompatibility of GQDs was re-validated (Figure 6a). In conclusion, the N-GQDs were internalized by the cells as shown in Figure $6 b$, where the controllable doping of GQDs was demonstrated [93]. 


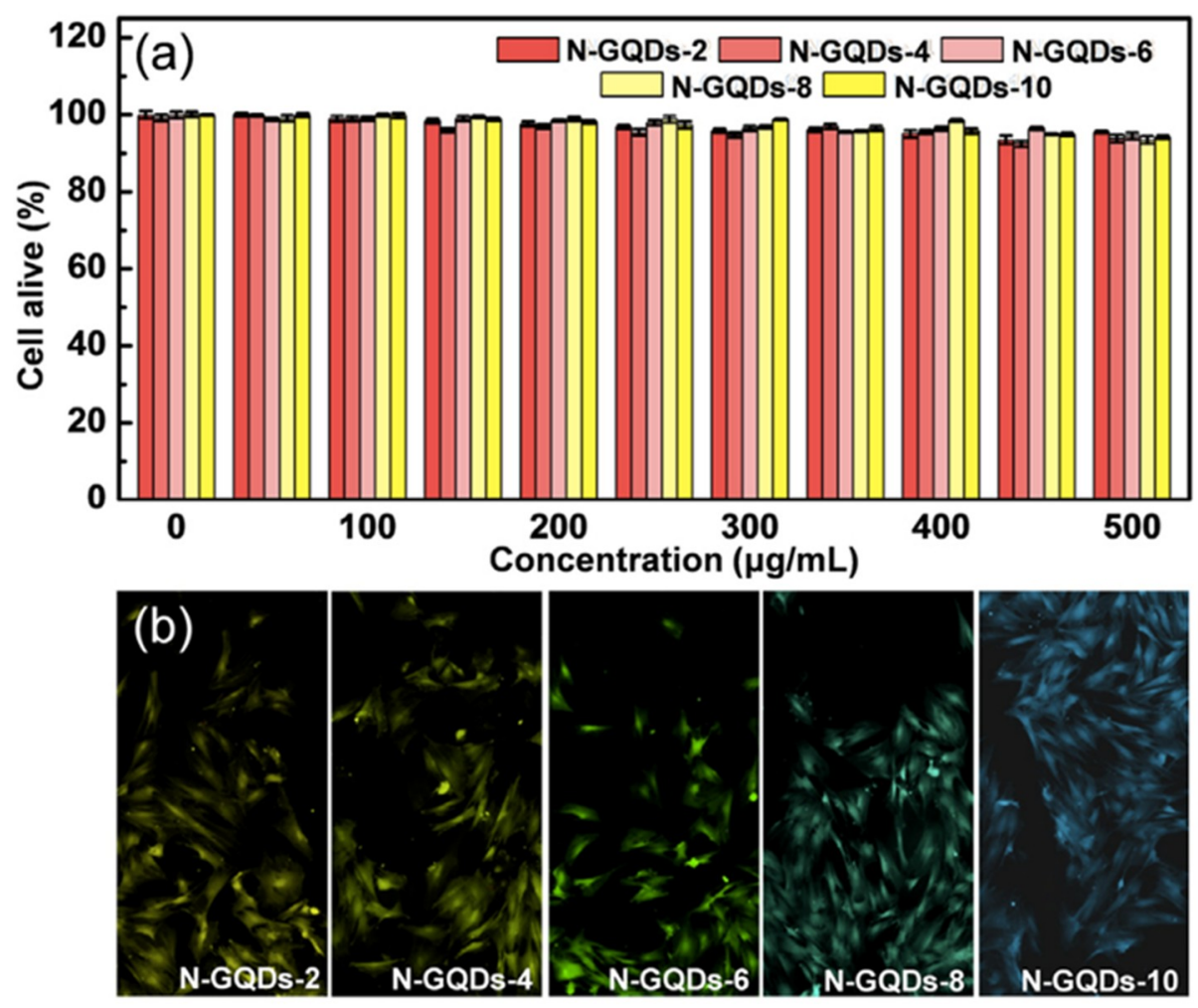

Figure 6. (a) Representation of concentration versus cell viability relation. Different reaction times (from $2 \mathrm{~h}$ to $10 \mathrm{~h}$ indicated as N-GQDs-2 to N-GQDs-10, respectively). (b) Confocal images of N-GQDs $(100 \mu \mathrm{g} / \mathrm{mL})$ incubated with fibroblast cells, indicating the internalization with different colors of emission [93].

The pentaethylenehexamine (PEHA) and penicillamine (DPA) co-functionalized GQDs, namely PEHA-GQD-DPA, as a fluorescence probe with 90.91\% QY have been successfully applied in the bio-imaging of $\mathrm{Hg}^{2+}$, which is one of the most prevalent heavy-metals that threatens human well-being. PEHA-GQD-DPA probe was shown to have an augmented fluorescence emission owing to their co-functionalization with PEHA and DPA and stated substantial photostability. Moreover, the existence of $\mathrm{Hg}^{2+}$ with PEHA-GQD-DPA, resulted in fluorescence quenching. This approach could qualify the optical detection of $\mathrm{Hg}^{2+}$ in natural water. The fluorescence response of Hg-PEHA-GQD-DPA complex towards various molecules, including glutathione (GSH), was studied and determined that GSH could generate an increased fluorescence intensity of Hg-PEHA-GQD-DPA complex. Consequently, the bio-imaging experiments conducted on $S_{480}$ cells showed that PEHA-GQD-DPA could image intracellular $\mathrm{Hg}^{2+}$ and GSH ultimately, where it was shown that $\mathrm{Hg}^{2+}$ could quench the fluorescence of the complex while GSH could well recover it. In this manner, the one by treatment of these substances with PEHA-GQD-DPA stained cell could enable the sequential detection of $\mathrm{Hg}^{2+}$ and GSH [62].

The bio-imaging activity of GQDs can also be considered along with their antibacterial property. In 2017, a study on adenine modified GQDs (A-GQDs) was reported, claiming for the first time that the synthesized QDs can be employed for the antibacterial applications under white light. Herein, A-GQDs were prepared by blending the bulk graphite and adenine (Figure 7). The synthesized A-GQDs were reported to be an exceptional in cell imaging due to their green TPFI property at an excitation wavelength of $750 \mathrm{~nm}$. In this study, the human lung carcinoma $A_{549}$ cells were selected as a test model, where the A-GQDs were shown to have high-grade biocompatibility and resulted into the cell viability at $94 \%$ after $24 \mathrm{~h}$ of incubation, which proved that A-GQDs could be the appealing candidates for further bio-imaging applications. The white light-activated antibacterial activity of A-GQDs against gram-positive $S$. aureus and gram-negative E. coli showed that there was nearly no 
significant proliferation and vital activity of E. coli, however S. aureus could stay alive without being affected by A-GQDs [61].
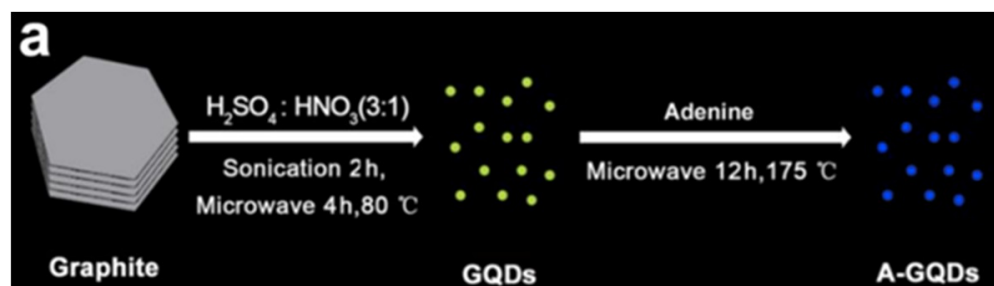

GQDs

A-GQDs
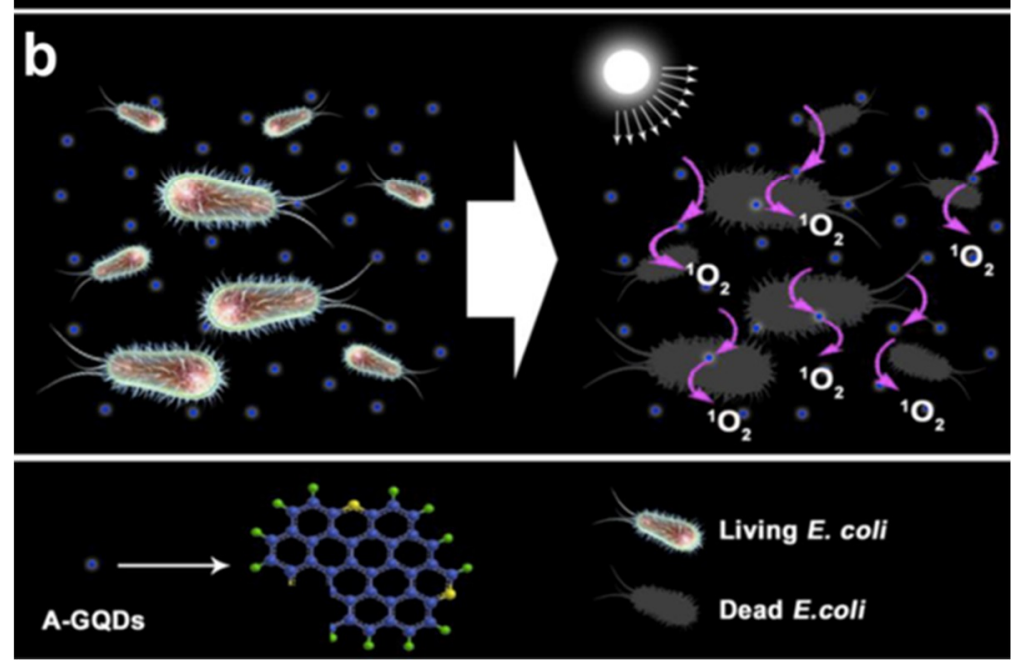

Figure 7. (a) Schematic illustration depicting the microwave-assisted preparation of A-GQDs. (b) White light-activated antibacterial property of A-GQDs towards E. coli. GQDs aqueous solution and adenine were reacted in a quartz tube for $12 \mathrm{~h}$ in the microwave reactor at $175{ }^{\circ} \mathrm{C}$ and left for $12 \mathrm{~h}$ at $4{ }^{\circ} \mathrm{C}$, subsequently filtered by a microporous membrane to remove the residual adenine. Two-day dialysis was performed to obtain a pure colloidal solution. After evaporation, A-GQDs were obtained for the further use. For the first time, it was shown that the adenine modified GQDs also own white light-activated antibacterial features along with their high fluorescence ability with a QY of $21.63 \%$ at $350 \mathrm{~nm}$ [61].

It was presented that various strategies could be developed for specifically targeting cells, or tumors in imaging applications [144-146]. Employing GQDs as imaging probes conjugated with targeting sites could be a good strategy for the cell-targeted bio-imaging applications. For instance, $\mathrm{Su}$ and coworkers designed a novel nanohybrid structure for concurrently visualizing and targeting cancer cells by taking full advantage of the optical properties of GQDs and the specific recognition capability of arginine-glycine-aspartate (RGD)-containing peptide nanofibers (PNFs). Since the RGD sequence could accurately recognize the integrin-rich solid tumor type, the labeling of tumor cells was successful. The biocompatibility test of the GQDs and RGD-GQDs compared to the control group generated a very promising result with substantial cell viability even after $72 \mathrm{~h}$. Moreover, it was hypothesized that the PNFs can be advantageous for cell reproduction, since the cellular viability was increased when incubated with PNF-GQDs (Figure 8) [11]. 


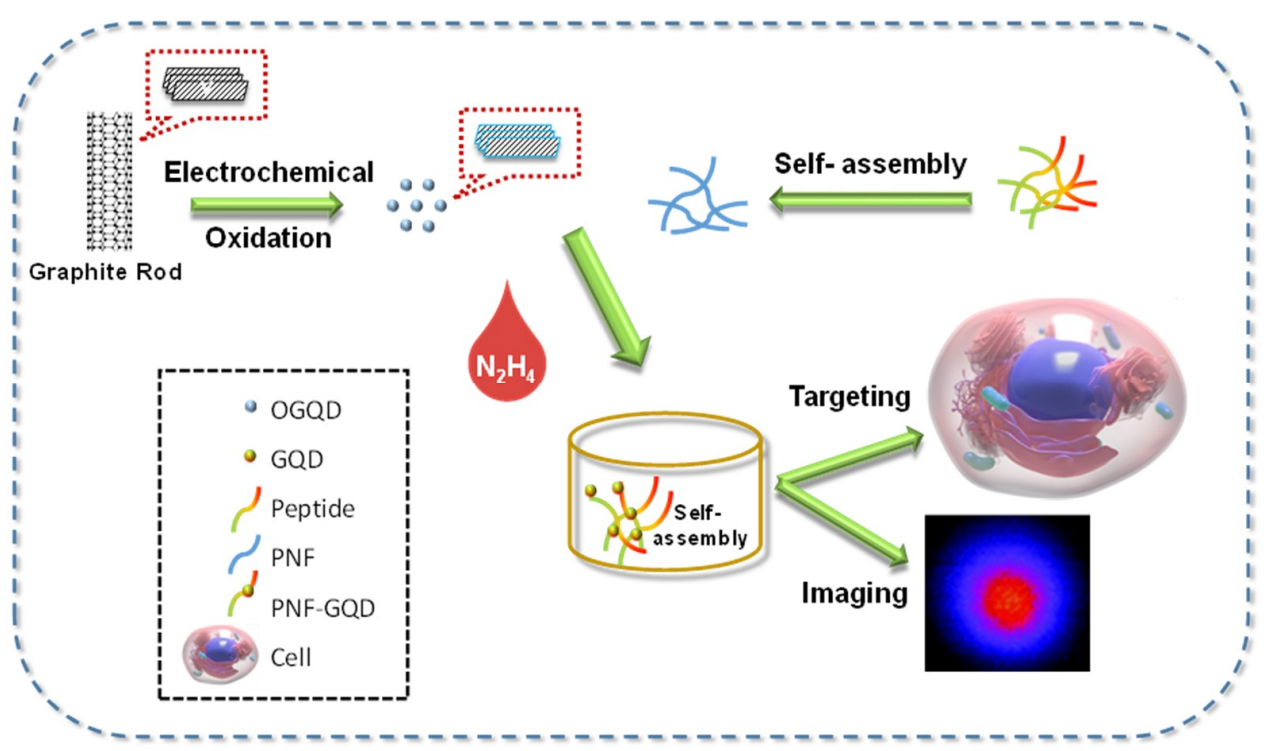

Figure 8. Schematic representation of the study in brief. The graphite rods were electrolyzed to the oxidized GQDs (OGQDs) and GQDs were synthesized by hydrazine hydrate reduction from OGQDs. Highly crystalline GQDs had 2-3 graphene layer with $0.25 \mathrm{~nm}$ lattice spacing. The peptide was designated to have AEAK sequence (for the self-assembly), RGD sequence (bind to integrins of the tumor), and YWYAF sequence (can bind to graphene). Subsequent to self-assembly, the PNFs were obtained with the height of $0.2-0.5 \mathrm{~nm}$. Afterward, PNF-GQD nanohybrids were formed and were ready for the further experiments in targeting and bio-imaging.

Progressively, another study published in 2018 also employed the RGD conjugated GQDs through $\pi-\pi$ stacking (RGD-GQDs) for the loading of doxorubicin (DOX), an anticancer drug, besides aiming for the cancerous cell imaging along with the monitoring of drug activity in the body. As aforementioned, the specific recognition ability of RGD along with excessive optical properties of GQDs make their conjugates the desirable candidates in targeted imaging studies. Moreover, by loading the anticancer drug DOX into this existing combination, a cancer-cell-destructive targeted cell delivery complex was constructed. In this case, it was advantageous that cancerous cells have lower $\mathrm{pH}$ values than the normal healthy cells, since the DOX released from the DOX-GQD-RGD complex could show a powerful trend in an acidic media. At the end of $72 \mathrm{~h}$ the most DOX release was significantly higher in the acidic media. The cytotoxicity results performed with $\mathrm{U}^{251}$ human glioma cells showed that GQD does not have a significant lethal effect, whereas both the DOX-GQDs-RGD and GQD-DOX lethal activity were superior to plain DOX treatment in glioma cells. This study also emphasized the potential of GQDs to be the $\mathrm{pH}$-responsive drug carrier vehicles [65].

That GQDs can get along with biological cells is a very important feature even though every study is not directly built for the diagnosis or in vivo imaging. This good relationship has facilitated the primary bio-imaging applications and is still being challenged by the novel methods and studies. It is critical that the internalized substance for the imaging should be ideally non-toxic for the cell, otherwise the cytocompatibility would hamper the bio-imaging applications. Thus, a combination of GQDs with different materials employed for various applications must be biocompatible. In this case, polyethyleneimine (PEI) conjugated GQDs can be a good example. The embedding or coating of GQDs with PEI provided separate colors to these particles stemmed from the structural difference in a non-toxic way for the human embryonic kidney and human primary glioblastoma cell lines. PEI attached GQDs formed the PEI 1800 and embedding GQDs into PEI formed PEI 600 materials that produced blue and red emissions, respectively. Uncoated GQDs emitted yellow light and could finely disperse in water along with the other GQDs. The PL-tunable properties with red and blue shifts were obtained by the interaction of PEI with GQDs [147]. However, this PEI and GQDs application does not exhibit any limitation, instead this can be adjusted for other imaging applications. 
In 2019, a different GQD-PEI study was conducted along with the phenyl bromide phosphine conjugation with GQDs (GQD-TPP). This study aimed to monitor targeted parts of the cell, where the GQD-PEI was expected to image the nucleus. Superior properties of GQDs facilitated the bio-imaging activity since GQD-PEI could perfectly target and label the cell nucleus. GQD-TPP was arranged for mitochondria imaging and similarly applied to mitochondria. The GQD-TPP viability was shown to be higher than GQD-PEI counterparts though both subjects were confirmed to be cyto-compatible. Thus, the low toxicity, low-cost properties when combined with photostable GQDs, this substance was recognized as a great candidate for prospective cell targeting and monitoring agents [110]. Another strategy to construct a bio-imaging platform for cell nuclei was proposed by Kumawat and coworkers. Herein, self-assembled GQDs (sGQDs) were bio-synthesized from grape seed extract (GSE) with a QY of $31.79 \%$. In the proposed method, sGQDs were prepared by dissolving grape extract in absolute ethanol and dried subsequent for the filtration. The self-assembly was formed by electrostatic interactions that occur between functional groups of nanomaterial and solvent, which was critical since these sGQDs could enter the cell nucleus due to their small sizes. Expectedly, sGQDs and GSE were biocompatible and non-toxic for the L929 cells as there was no ROS generation. In vitro scratch assays showed that sGQDs indeed have proliferative cellular activity. Moreover, sGQDs were managed to enter fibrosarcoma, pancreatic cancer, ovarian cancer, and osteosarcoma cell lines, and they self-localized themselves inside the nucleus of these cells (Figure 9). As a result, this phenomenon demonstrated that, sGQDs are advantageous in terms of the superiority they show over other nucleus dyes because these dyes are not highly photo-sensitive, besides they are difficult to be handled as well as expensive. However, these green-synthesized sGQDs can uniquely image nuclei while being highly effective with a small surface to volume ratio and self-localization characteristics inside a nucleus [30].

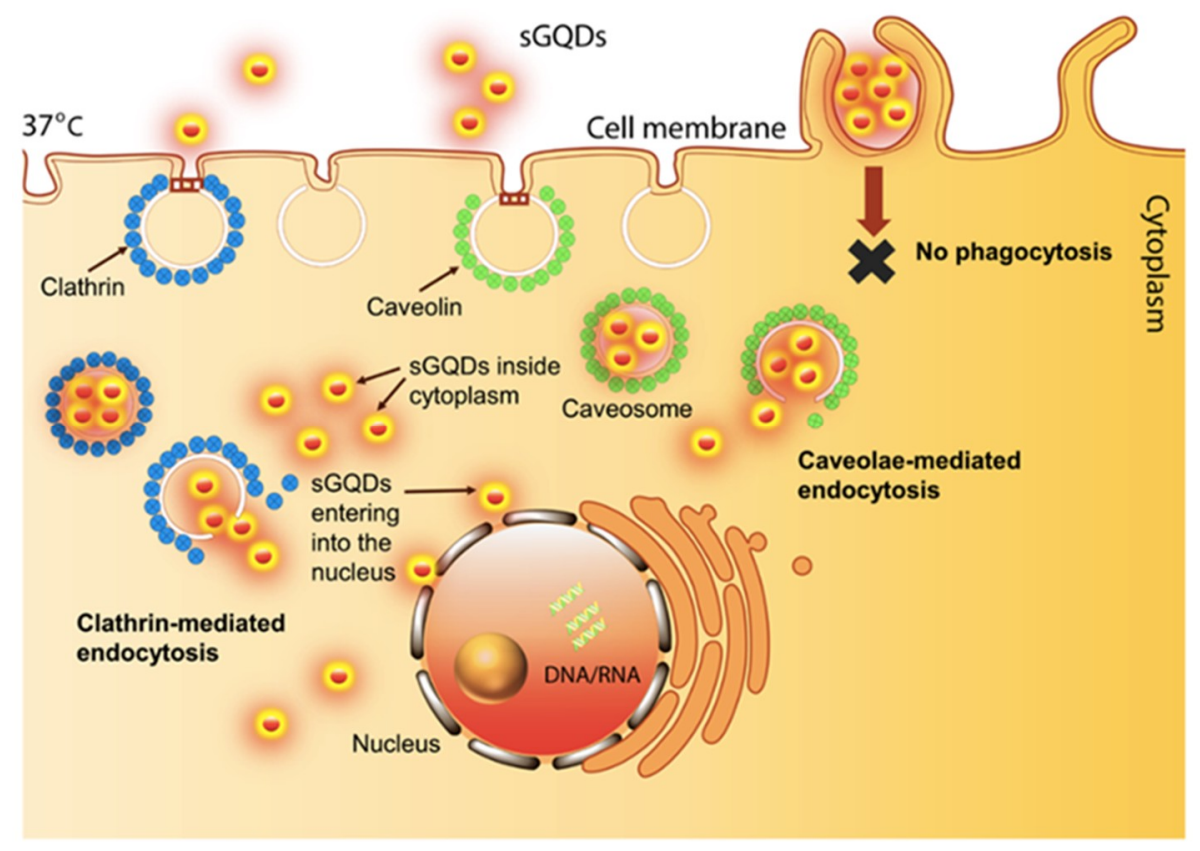

Figure 9. Nucleus labeling was performed when sGQDs were directed towards the cell nucleus by themselves. The figure represents the cellular and nuclear uptake of the sGQDs by endocytosis mediated by clathrin and caveolin endocytosis inside the cell. The uptake mechanism shows the localization of sGQDs inside the nucleus. Even though the sGQDs could not bear any nuclear localizing agent, according to the previous studies, their small size, surface charge, histone-chaperones, and nuclear-localization signals execute localizing inside the nucleus. Thus, the nucleus imaging and potential drug delivery applications with sGQDs are more likely to happen with their eco-friendly features. In addition, with no ROS generation, this nucleus staining method is confirmed to be biocompatible and non-cytotoxic [30]. 
Lately, GQDs mediated bio-imaging applications were being elevated due to their significant bio-applicable properties. Instead of only offering in vitro observation of the luminescence they exhibit, the experiments conducted in vivo are being executed and are the elaborative and promising site of the imaging applications. Moreover, these in vivo studies can be aimed for the imaging of targeted parts of the body. Liu et al. prepared the europium-GQDs complex with dibenzoylmethane (DBM) and 1,10-phenanthroline (Phen) that demonstrated red fluorescence with high water solubility, 15.5\% QY, and high color purity. Due to the enhanced permeability and retention (EPR) effect, the as-prepared complex was expected to stain tumor site with its bio-imaging capability. The in vivo and ex vivo experiments showed very good PL in the tumor site when interacted with the europium-GQDs complex. However, it should be also noted that, rather than only tumorous site, other organs were also weakly luminescent. These results are promising in terms of diagnosis and rapid intervention to the tumor site in the body. Nevertheless, such studies are speculated to be developed in the near future for particular and precise applications [64].

Due to EPR effect, the accumulation of nanosized particles into the tumor site is expected. The endothelial layer is weakened around the tumor tissue and vascularization occurs densely while retaining the macromolecular structures [148]. It is plausible to take advantage of EPR while designing anticancer systems. On the other hand, actively targeting the tumor folate receptors with folic acid (FA) is an alternative approach to tumor targeting for therapeutic purposes which is now becoming more and more prevalent. It was shown by various studies that FA can selectively target folate receptors found on tumor cells [149-151]. Hence, the conjugation of FA and PEG with GQDs along with ${ }^{131}$ I justified the tumor cell targeting and single-photon emission computerized tomography (SPECT) imaging by Wang and coworkers in 2019 [152]. According to their findings, PEG prompted the biocompatibility of the GQDs, and FA could target the folate receptors. The complex of ${ }^{131}$ I-GQDs-PEG-FA was safe for experimental conditions. Moreover, this complex can be metabolized in two days and can be excreted by urination. This accounted for an efficacious radioactive imaging probe for the tumor cells.

So far, the lab-scale production of the GQDs for the target aimed applications was the focus of interest. However, it is also possible to design large-scale-fit GQDs for industrial purposes. In 2013, a study suggested that large scale GQDs can be managed to be synthesized by an improved Hummer's method. Even though the as-prepared GQDs showed low QY like 1\%, the good biocompatibility on the A 549 cells along with hydrothermal therapy for the QY was promising for further studies [57]. Later on, other methods revealed the large-scale synthesis of GQDs for various purposes [153-155]. However, in 2016, Wang et al. introduced the large-scale production of GQDs based on the carbon amounts of rice husk biomass. Just like the most of the GQDs, these as-prepared particles also demonstrated great biocompatibility when tested with HeLa cells along with blue PL [156]. In the same year, high defect(HD-GQDs) and low defect-GQDs (LD-GQDs) were synthesized by exfoliation in order to be used in bio-imaging as fluorescence probes. Cell imaging investigated with the fibroblast L929 cells showed that the GQDs were blue luminescent when exposed to $365 \mathrm{~nm}$ irradiation and proved to be potential visualization tools with substantial biocompatibility [67]. In 2017, Wang et al. produced high quality sulfonated-GQDs at an industrial-scale for bio-imaging the Golgi apparatus. The significance was due to both high-quality and particular Golgi imaging rather than whole cell imaging [28]. A study that employed both GQDs and CNDs showed the different PL properties of these dots. GQDs did show two characteristic absorption peaks and CNDs had only one; where the GQDs had higher stability and low photobleaching property. The industrial scale mass production was supported by the convenient room temperature synthesizable characteristics of these carbon derived dots with toxic-free nature and high QY of 17.5\% for GQDs and 35.3\% for CNDs. Since the HEp-2 cells showed staining property when interacting with these carbon dots, the bio-imaging applications were also revealed to be possible by this study [97]. 


\section{Role of GQDs in Therapy Development}

Amidst some graphene-based nanomaterials such as GO, fullerenes, carbon nanotubes (CNTs), GQDs show a significant potential for therapy development in nanomedicine and biotechnology $[157,158]$. Their exceptional properties discussed in the earlier section render them the new promising tool for biosensing [89], biomedical imaging [63], drug delivery [46], and photo-thermal and photodynamic therapy $[42,98]$.

As previously mentioned, GQDs are arousing a great interest in the application of drug delivery, specifically for anticancer therapy and Alzheimer's treatment. Drug delivery systems (DDS) transport the pharmaceutical compound into the human body in order to fully achieve their medicinal effect $[113,159-161]$. GQDs have been used as drug carriers by taking advantage of their $\pi-\pi$ interactions, their small size and their ability to conjugate their surface with targeting ligands [162]. Moreover, functionalized GQDs have shown substantial efficiency on recognizing cancer receptors, selectively delivering chemotherapeutic agents, such as doxorubicin (DOX) or cisplatin, to the cell nucleus while enhancing their cytotoxicity, hindering their incorrect distribution into normal cell tissues and preventing drug resistance $[163,164]$. Liu et al. proved the viability of producing a multifunctional DDS (Figure 10) using fluorescent GQDs covalently linked with targeting arginine-glycine-aspartic acid (RGD) peptides for the enhanced delivery of DOX into prostate cancer cells [165]. Furthermore, many studies have confirmed the improved bioavailability of GQDs and the increased nuclear accumulation as well as DNA fragmentation activity of the therapeutic drugs [166]. Zhou et al. reported the good embedding ability of small-sized GQDs toward DNA cleavage [167]. These GQDs were synthesized from GO using a Fento reagent $\left(\mathrm{Fe}^{2+} / \mathrm{Fe}^{3+} / \mathrm{H}_{2} \mathrm{O}_{2}\right)$ under UV irradiation and their wide applications were further investigated using copper ions $\left(\mathrm{Cu}^{2+}\right)$ in a DNA cleavage system. This research group proved that by using GQDs and $\mathrm{Cu}^{2+}$ a significantly higher amount of DNA could be modified into non-continuous DNA than by employing GO and $\mathrm{Cu}^{2+}$. Presumably, the small lateral size of GQDs allowed them to easily insert themselves between the DNA molecules, causing the aforementioned cleavage.

Amyloidosis is a well-known aggregation and deposition of amyloid proteins as cross-beta sheets or fibrils in plaques around cells leading to organ and tissue failures. This phenomenon is responsible for a great number of degenerative disorders such as Alzheimer's disease, Parkinson's disease, type 2 diabetes, as well as for providing stability to bacterial biofilms [168-173]. Therefore, various candidates for the inhibition of amyloid aggregation, such as small molecules and peptides, have been studied over the years $[174,175]$. Protein accumulation inhibitors generally try to substitute the hydrogen bonding, hydrophobic interaction, and $\pi-\pi$-stacking of the amyloid protein to disassemble their aggregation [173]. GQDs have been reported as outstanding inhibitors of aggregation, toxicity of pathogenic and functional amyloid species due to their functionalized surface, which improves their antiamyloid targeting and delivery [175].

Alzheimer's (AD) and Parkinson's diseases (PD) are two of the most common chronic neurodegenerative disorders, which are gradually responsible for the deterioration of both the mental as well as physical activities of a subject, respectively. These disorders are characterized by the aggregation of $B$-amyloid $(A B)$ and a-synuclein (a-syn) peptides respectively, causing extracellular amyloid plaques in the brain $[169,176]$. Due to some therapeutic deficiencies-such as low in vivo stability and efficacy, negligible permeability in the blood-brain barrier, and complex fabrication-many aggregation inhibitors for $A ß$ and a-syn peptides have been ruled out as non-beneficial biomedical agents for either AD nor PD treatment [177-179]. Liu et al. presented the efficiency of using GQDs as a low-cytotoxicity inhibitor for the agglomeration of Aß peptides as they attach themselves to the hydrophobic center of the peptides [180]. This work demonstrated the possible biomedical application of GQDs as an anti-AD treatment due to their quantum confinement effect, edge effect, and remarkable biocompatibility. In addition, Kim et al. reported the advantages of GQDs as an anti-aggregation agent for PD by directly interacting with mature a-syn fibrils leading to their fragmentation [179]. Human islet amyloid polypeptide (IAPP) is another acclaimed amyloid protein that can be triggered by many 
biological, environmental, and chemical factors into ß-sheets structured agglomerations and is also a distinctive mark of type 2 diabetes [181]. Wang et al. exhibited GQDs as an efficient candidate for the prevention of IAPP accumulation and toxicity in an embryonic zebrafish due to their electrostatic and hydrophobic interactions [182]. The aforementioned inhibition of IAPP conversion into cross- $\mathbb{B}$ fibrils resulted into aggregation due to the presence of strong hydrogen bonds, aromatic stackings as well as salt-bridges between GQDs and the amyloid protein.
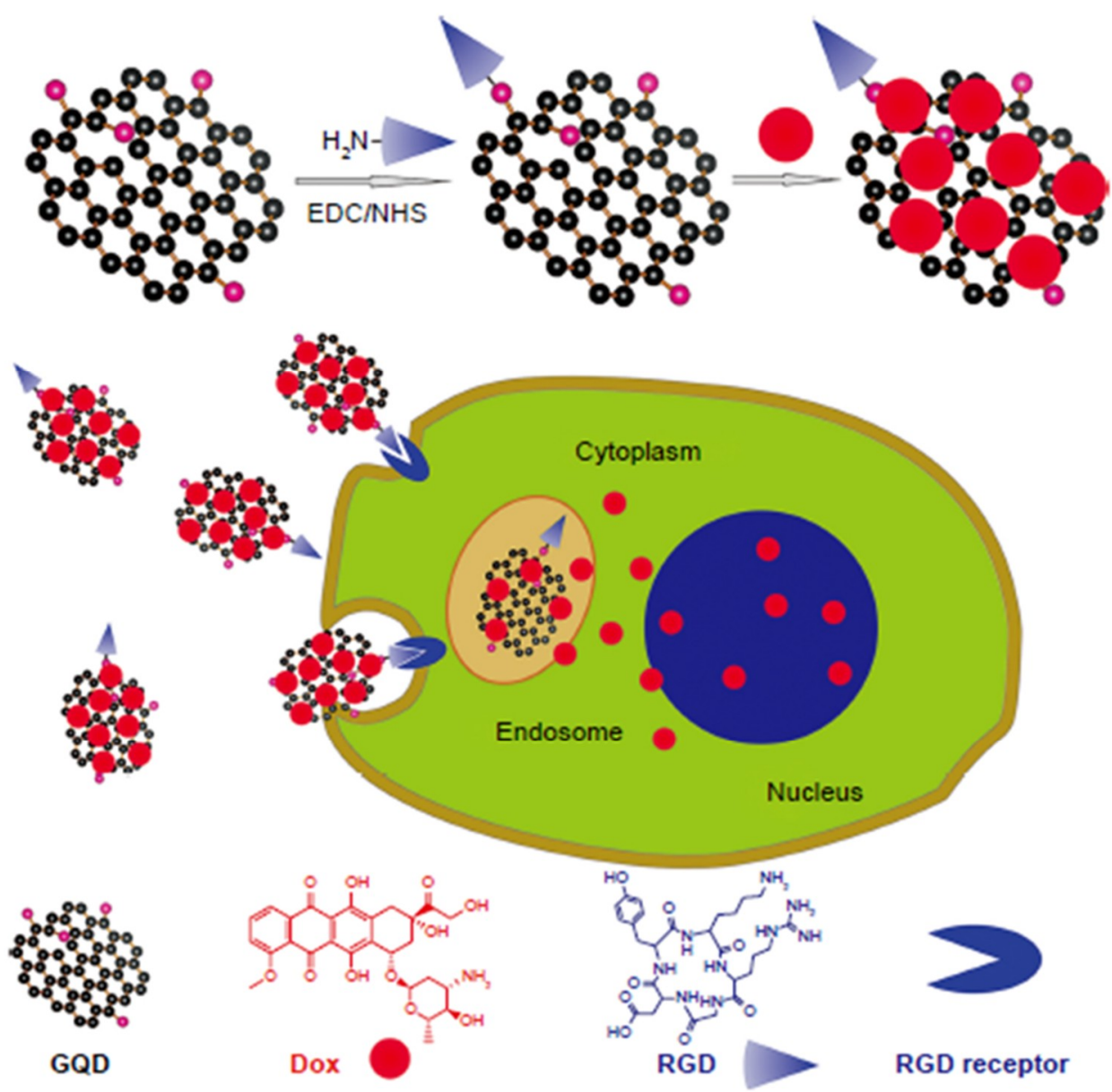

Figure 10. Schematic representation of multifunctional GQD-based DDS for the targeted delivery of DOX and their interactions with prostate cancer cells [166]. DOX, doxorubicin; RGD, arginine-glycine-aspartic acid; EDC/NHS, 1-(3-(dimethylamino)propyl)-3-ethylcarbodiimide and N-hydroxysuccinimide.

As previously mentioned, amyloidosis can also be found in bacterial biofilms. These biofilms consist of structural and functional microbial communities that are also responsible for various severe illnesses [172,173]. Chapman et al. reported the first functional amyloid protein, CsgA, found in the curli fibrils from E. coli and other bacteria [183]. Other human microbiomes-such as Streptococcus, Staphylococcus, and Salmonella-have presented the same structural and biophysical properties for extracellular amyloid aggregation found in E. coli [171]. Wang et al. studied the antibacterial properties of GQDs with biofilms of Staphylococcus aureus [173]. GQDs was determined as a potential therapeutic agent for the disassembly of such biofilms due to their high ROS production, membrane breakage, and their small size [173].

An additional clinical application of GQDs is the photothermal therapy (PTT) for cancer treatment. PTT is a non-invasive substitute for conventional cancer therapy that operates with the use of laser light and electromagnetic radiation distributed into the contrast material applied to the cancer region causing thermal damage [184]. The presence of large $\mathrm{sp}^{2}$ carbon agglomeration on the GQDs surface 
and the carboxyl groups attached around the edges enable the incorporation of highly aromatic drug molecules using the $\pi-\pi$ interactions of the GQDs [185]. Li et al. demonstrated that GQDs presenting these above-mentioned characteristics show great water solubility and suitability for conjugation with ligands such as folic acid (FA) and an outstanding load-bearing capability for theranostic agents, namely IR-780 iodide, which renders the GQDs the ideal candidate for PTT and targeted tumor imaging [186].

With the continuous development of nanotechnology for biomedical applications, the incorporation of graphene-based nanomaterials in photodynamic therapy (PDT) has exhibited great therapeutic improvement [187]. PDT can be used as an oncologic intervention that involves oxygen and the exposure of photosensitizers (PSs) to specific wavelengths of light in order to damage cancer tissue [188] as well as an antimicrobial technique to eliminate bacteria by light irradiation [189]. The PS molecules absorb the emitted light—i.e., ultraviolet (UV) or visible (VIS)—which promotes them from the ground state to an excited triplet state passing through an intermediate singlet state, resulting in the generation and release of ROS, such as the singlet oxygen $\left({ }^{1} \mathrm{O}_{2}\right)$, at the targeted cell [190]. However, some PS molecules may undergo a fluorescent process in which they fall from the excited state to a lower energy state by releasing a photon [69]. These fluorescence properties of some PS have been used for real-time medical detection and bio-imaging of various diseases such as cancer, Alzheimer's, etc. $[69,108]$. These multi-functional PSs are known as theranostic agents, as they work for both medical diagnostics and therapy. Even though many clinical advantages have been attributed to PDTs such as minimal invasion, non-cumulative toxicity and extraordinary functional and medical results, some limitations on selecting the most adequate photosensitizer and the appropriate light intensity may difficult their effective application for clinical treatments [187]. Currently, PSs do not only attack the targeted malignant cells, but as light irradiation must be implemented for target treatment, this can also generate ROS in both normal and healthy cells, damaging them irreparably [191]. Nevertheless, the use of GQDs may assist on overcoming the previously mentioned challenges of choosing the ideal PS due to their excellent catalytic activity, genuine fluorescence properties, and good photo stability [192].

According to a study by Tabish et al., GQDs can be engineered to be cyto-compatible in PDT applications considering its promising singlet oxygen generation ability while it can be synthesized with high QY that support their PDT application. GQDs are confirmed to have impressive electron conducting network, photo-stability, corrosion resistance, as well as water dispersibility and pH stability that are useful for PDT applications [103]. The simplification of the principle behind killing the tumors by PDT is stemming from the fact that a photo-activated PSs can generate singlet oxygen inside the tumor cell which results in oxidative stress generation and cell death. ROS generation is mainly dependent on the type of the graphene and the route of their administration [108]. For instance, Zhou et al. showed that when GQDs lack different groups—such as carboxyl, ketonic carbonyl, or hydroxyl-their ROS generation ability varies as well and GQDs generate ROS in correlation with the oxygen content of the GQDs structure. As with their photostability, ROS generatability was affected from this situation [193]. Ahirwar et al. showed that the breast cancer cells were killed by $90 \%$ only in 5 min of exposure due to singlet oxygen generation when they employed GQDs as PSs [68]. Li et al. demonstrated that fluorine containing GQDs can generate more singlet oxygen QY compared to pristine GQDs indicating better PDT agent characteristics. Zhang et al. produced a PDT agent with GQD-decorated up-conversion nanoparticles (UCNP-GQD) using tetramethylrhodamine-5-isothiocyanate (TRITC) as mitochondria-targeting ligand for therapeutic cancer treatment [194].

GQDs show excellent properties as electron donors as well as electron acceptors and at the same time functioning as a theranostic agent and an outstanding source for ROS [160]. Furthermore, GQDs are able to generate cytotoxic ROSs by converting biomolecules from normal species such as ${ }^{3} \mathrm{O}_{2}$ to ${ }^{1} \mathrm{O}_{2}$ via electron transfers and light exposure makes them an exceptional PDT agent with the highest QY reported so far $(Q Y>1.3)[159,195,196]$. In addition, the free radicals present at the GQDs surface and the capacity to transfer energy directly into oxygen molecules are considered the main causes in the generation of high amounts of ${ }^{1} \mathrm{O}_{2}$ [196]. Kuo et al. reported the use of N-GQDs as a PS to eradicate microbes, in this case the bacterium E. coli, and to replace antibiotic treatments using 
PDT [188]. This work exhibited the promising electrocatalytic, photochemical, and electrochemical properties of N-GQDs as well as their capacity of producing more ROS, which are responsible for enhancing the PDT effect.

\section{GQDs as Potent Electrode Material for the Development of Micro-Supercapacitors (MSCs)}

Considering the increased demand for wearable and portable electronics such as flexible displays and electronic textiles, the advancement in flexible energy-storage devices has now become highly crucial and interesting [197-199]. In the last few years, owing to a high demand for lightweight and flexible portable energy storage devices, electrochemical capacitors or supercapacitors have garnered enormous attention and have exposed tremendous potential for portable electronic devices [200-204]. They are utterly distinct from the conventional capacitors and can fill the void between lithium-ion batteries and traditional capacitors. In fact, supercapacitor materials serve the merits of both rechargeable batteries as well as dielectric capacitors, which make them ideal candidates to acquire operational safety, fast charge-discharge ability, long shelf-life, low maintenance cost, and high power density [205-208].

To attain wearability and portability, the architecture of flexible power sources is quite significant for designing wearable micro-supercapacitors (MSCs) [209]. Flexible fiber supercapacitors (FFSCs) are being studied as one of the most trustworthy flexible power sources due to their extended cycling time, easy operation, quick charge-discharge rate, and enhanced power delivery. In addition, FFSCs are versatile because of their distinct wire-shaped assembly and can be readily altered in accordance with the requirement to develop MSCs [209,210].

MSCs can be classified on the basis of how the active components reserve the energy. They can be either electric double layer capacitance (EDLC) supercapacitors or pseudo-capacitors. The former works on storage of charge via physical ionic deposition, whereas the latter via redox reactions [211]. In recent years, various materials such as composite materials [212], carbon-materials [213], metal oxides [214], and conducting polymers [215,216] have been established as electrode materials for the fabrication of micro-supercapacitors. Among these, carbon-based micro-supercapacitors have been extensively studied because of their wide pore size distribution, excellent conductivity, large surface area, as well as high cycle stability of carbon electrode materials [45,217-224]. The majority of carbon electrode materials include carbon fibers (CFs), graphene, CNTs, carbon dots, and GQDs [225-228].

GQDs serve as an electrode material for MSCs, particularly due to their excellent quantum confinement and edge effects. Highly doped GQDs (e.g., C-, N-, and O-doped GQDs) could provide a high concentration of active sites due to the co-doping as well as most marked edge effect, which can result in higher specific capacitance [229,230]. In addition, graphene sheets (GS) are also considered as a good electrode material for high-performance supercapacitors [231,232]. When compared to GS, GQDs possess nanometer-size, better solubility in wide range of solvents, and abundant edge defects, making them more appropriate for developing micro-supercapacitors $[233,234]$.

For flexible all-solid-state supercapacitors, N-GQDs can act as remarkable pseudo-capacitive materials when assembled on carbonized metal-organic framework (MOF) materials integrated with CNTs to synthesize hierarchical 3D all-carbon electrode materials [235]. In such a system, CNTs and carbonized MOF materials provide electrical conductivity and higher surface area, respectively. It was reported that, owing to the combined additive effect of the aforementioned components, the resulting micro-supercapacitor could offer energy density of $18.75 \mathrm{Wh} \mathrm{kg}^{-1}$ with a power density of $108.7 \mathrm{~W} \mathrm{~kg}^{-1}$ and high specific capacitance of $540 \mathrm{~F} \mathrm{~g}^{-1}$ at a current density of $0.5 \mathrm{~A} \mathrm{~g}^{-1}$ [235]. The greater edge-to-core atomic ratios exhibited by N-GQDs could enhance electrolyte wettability. This design could be able to operate economic light emitting diodes for about 20 min, which directs a new path for high-performance energy storage fields [235].

Carbon-based FFSCs are favorable power sources for wearable and portable electronic devices. A study reported the synthesis of N-GQDs/CF hybrids using graphene hydrogel (GH) [209]. This GH could serve as a $3 \mathrm{D}$ porous buffer layer, which was implanted on CF to obtain ternary carbon 
hybrid of N-GQD/GH/CF (Figure 11). Herein, N-GQDs with high pseudo-capacitive performance were electrochemically deposited on the GH/CF layer. Such a micro-supercapacitor could provide a volumetric capacitance of $93.7 \mathrm{~F} \mathrm{~cm}^{3}$ at $20 \mathrm{~mA} \mathrm{~cm}^{3}$, which was almost 7-fold more than that of the $\mathrm{GH} / \mathrm{CF}$, whereas the capacitance retention reached $88 \%$ after 5000 cycles. The improved performance and excellent flexibility of FFSCs can be attributed to the presence of N-GQDs in such a system [209].

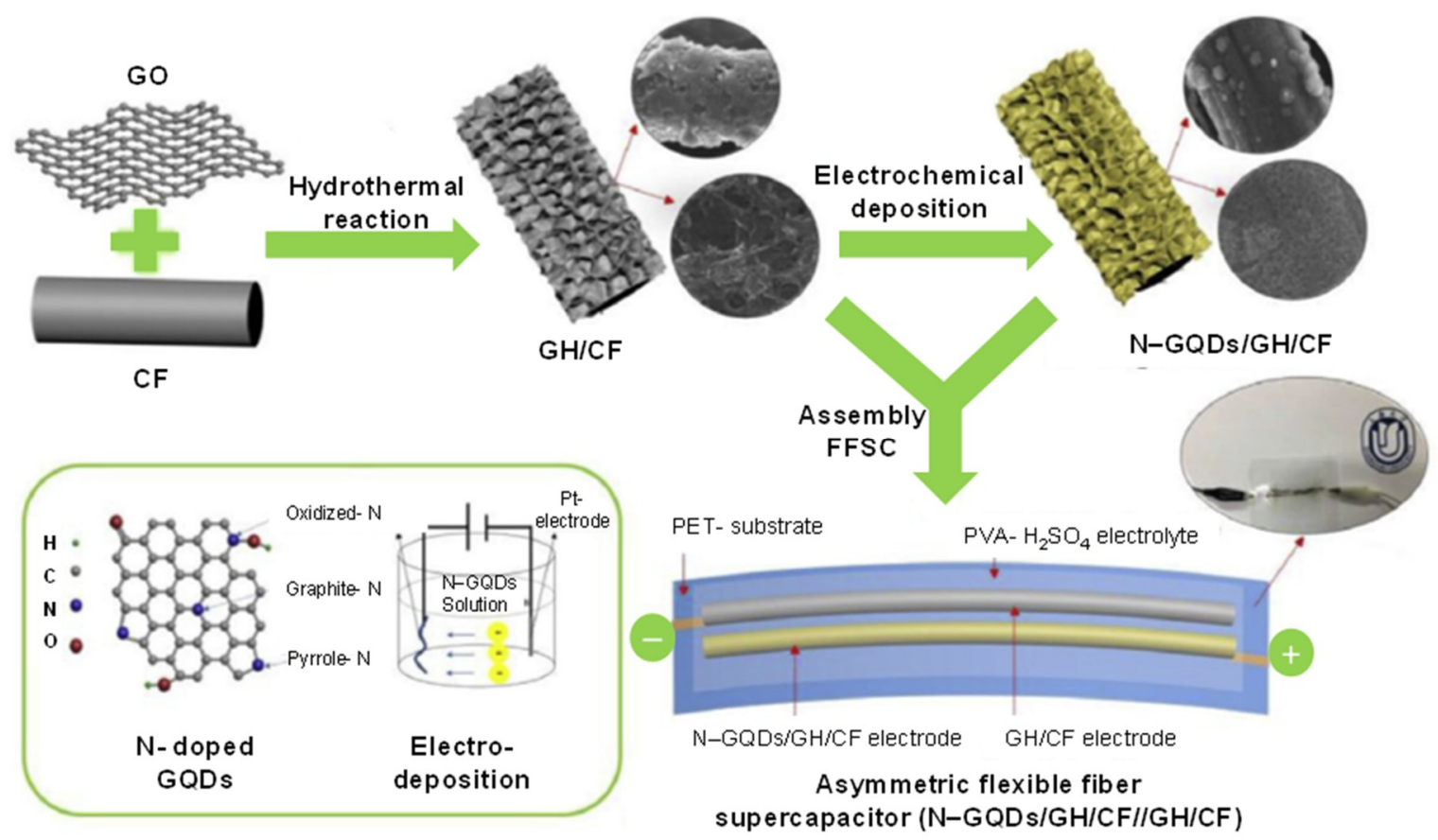

Figure 11. Schematic representation of the fabrication process of the N-GQD/GH/CF positive electrode and GH/CF negative electrode and their assembly into an asymmetric FFSC [209].

Currently, mechanically flexible as well as optically transparent energy storage appliances are being studied and developed owing to their high ability to act as integrated power sources [210]. Lee et al. designed such a flexible and transparent micro-supercapacitor based on GQDs and chelated graphene using the electrophoretic deposition (EPD) technique. In this work, GQDs were robustly incorporated on an interdigitated framework of monolayer graphene due to the formation of chelate between GQDs and graphene with metal ions. The subsequent resultant pattern was employed as the potent electrode material for micro-supercapacitor. This device could exhibit a high energy storage and excellent transparency of $9.09 \mu \mathrm{F} \mathrm{cm} \mathrm{cm}^{-2}$ and almost $93 \%$, respectively [210].

$\mathrm{N}$-doped porous carbon synthesized by implanting N-GQDs onto a carbonized metal-organic framework (cMOF-5) can serve as an electrode material for micro-supercapacitors, where N-GQDs offers enhanced pseudo-capacitance as well as increased surface wetting ability and cMOF-5 offers a cubic porous pattern with a higher electro-conductivity as well as greater specific surface area. Such an N-GQD/cMOF-5 electrode material could generate a specific capacitance of $294.1 \mathrm{~F} \mathrm{~g}^{-1}$ at $0.5 \mathrm{~A} \mathrm{~g}^{-1}$ and $780 \mathrm{~F} \mathrm{~g}^{-1}$ at $10 \mathrm{mV} \mathrm{s}^{-1}$ in a three-electrode system [39].

Combining 3D graphene (3DG) framework with other functionally active components increases the overall ability of micro-supercapacitors [236]. As presented in Figure 12, GQDs were electrochemically incorporated onto the 3DG framework. The researchers reported that such a highly stable MSCs system engineered from the GQD/3DG could exhibit high specific capacitance of $268 \mathrm{~F} \mathrm{~g}^{-1}$, which was 90\% improved than those with only 3DG electrodes [234]. 


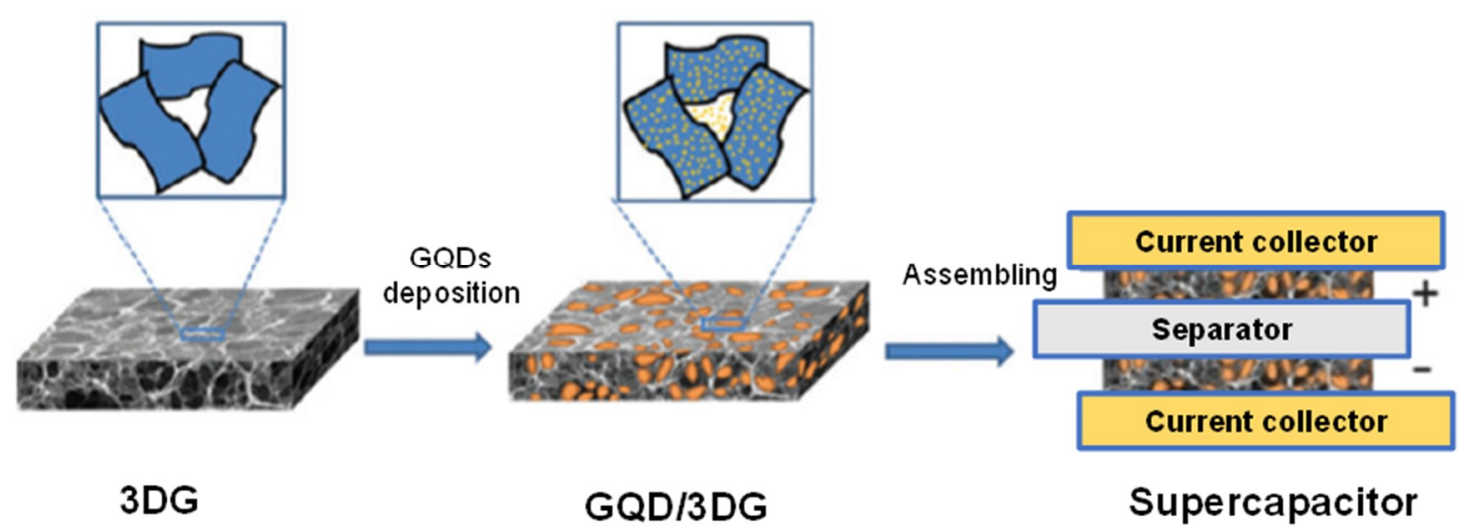

Figure 12. Schematic illustration of a GQD/3DG based symmetrical micro-supercapacitor [234]. Reproduced by permission of The Royal Society of Chemistry.

Ouyang et al. reported a hydrothermal top-down synthetic approach for the production of $\mathrm{S}$, $\mathrm{N}$-GQDs, which could exhibit a high specific capacitance of $362.60 \mathrm{~F} \mathrm{~g}^{-1}$ at a fixed scan rate of $5 \mathrm{mV} \mathrm{s}^{-1}$. This high performance was resulted from the pseudocapacitance offerred by $\mathrm{S}$ and $\mathrm{N}$. This doping could improve the charge storage capacity [237]. Mondal et al. synthesized GQD-doped polyaniline fibrous composites, which could show good cyclic stability and a retention life time of $80.1 \%$ after 3000 cycles. It was reported that these as-prepared GQDs exhibited specific capacitance value of about $1044 \mathrm{~F} \mathrm{~g}^{-1}$ at a current density of $1 \mathrm{~A} \mathrm{~g}^{-1}$ [238]. GQDs with size $<5 \mathrm{~nm}$ when prepared by top-down approach using nitric acid (HNO3) as a reaction precursor could show high electrochemical performance for the development of MSCs [239]. Such a GQDs-based system could provide an ideal EDLC features including high cycling stability, negligible relaxation duration, small internal resistance, good energy density of $41.2 \mathrm{~W} \mathrm{~h} \mathrm{~kg}^{-1}$ at $1 \mathrm{~A} \mathrm{~g}^{-1}$ and an excellent specific capacitance of $296.7 \mathrm{~F} \mathrm{~g}^{-1}$. These characteristics demonstrated the enhanced electro-conductivity and improved ion transferability [239].

Generally, carbon-based micro-supercapacitors working on the principle of EDLC are limited by the energy loading densities and quite low specific capacitances and energy, since the corresponding electrode materials are derived from weakly active and huge carbon components [240]. To overcome this drawback, strongly active $\mathrm{N}$ and $\mathrm{O}$ co-doped GQDs can be used to obtain abundant active sites, increased hydrophilicity and extremely smaller sizes [240]. In a study reported in 2018, N-O-GQDs MSCs could offer higher volumetric capacitance of $325 \mathrm{~F} \mathrm{~cm}^{3}$ in sulfuric acid owing to their elevated electrolyte wettability, high storage density, and excellent pseudo-capacitance property [240].

Tjandra and colleagues reported that GQDs can also be combined with materials to fabricate freely placed and flexible EDLC supercapacitor electrode [211]. Herein, hydrothermally synthesized GQDs were electrodeposited on carbon cloth to improvise its capacitance up to $70 \mathrm{mF} \mathrm{cm}^{-2}$ without any significant mass charging. Another EDLC supercapacitor electrode by electrodepositing GQDs, but on CNTs provided an enhanced capacitance of $44 \mathrm{mF} \mathrm{cm}^{-2}$, which was around twice as high as just using CNTs [233].

Halloysite nanotubes (HNTs) that are rich in active sites for storing energy, when combined with GQDs can be employed for the development of eco-friendly supercapacitors. Ganganboina et al. reported such a device using GQDs/HNTs nanomaterials (Figure 13) in the co-existence of APTES (3-aminopropyl-triethoxysilane) to offer rapid charge transfer and accelerated charge storage sites [241]. Moreover, it could provide specific capacitance of 363 and $216 \mathrm{~F} \mathrm{~g}^{-1}$ at current densities of 0.5 and $20 \mathrm{~A} \mathrm{~g}^{-1}$, respectively. In other studies, the same group has developed similar MSCs, but by assembling $\mathrm{Fe}_{3} \mathrm{O}_{4}$ along with GQDs/HNTs to generate even higher specific capacitance (i.e., $418 \mathrm{~F} \mathrm{~g}^{-1}$ ) [242]. The $\mathrm{Fe}_{3} \mathrm{O}_{4} / \mathrm{HNTs}$ could enhance the active sites for charge storage by reducing the diffusion path of electrons. Table 3 highlights the specific capacitance values corresponding to some more GQD-based supercapacitors. 


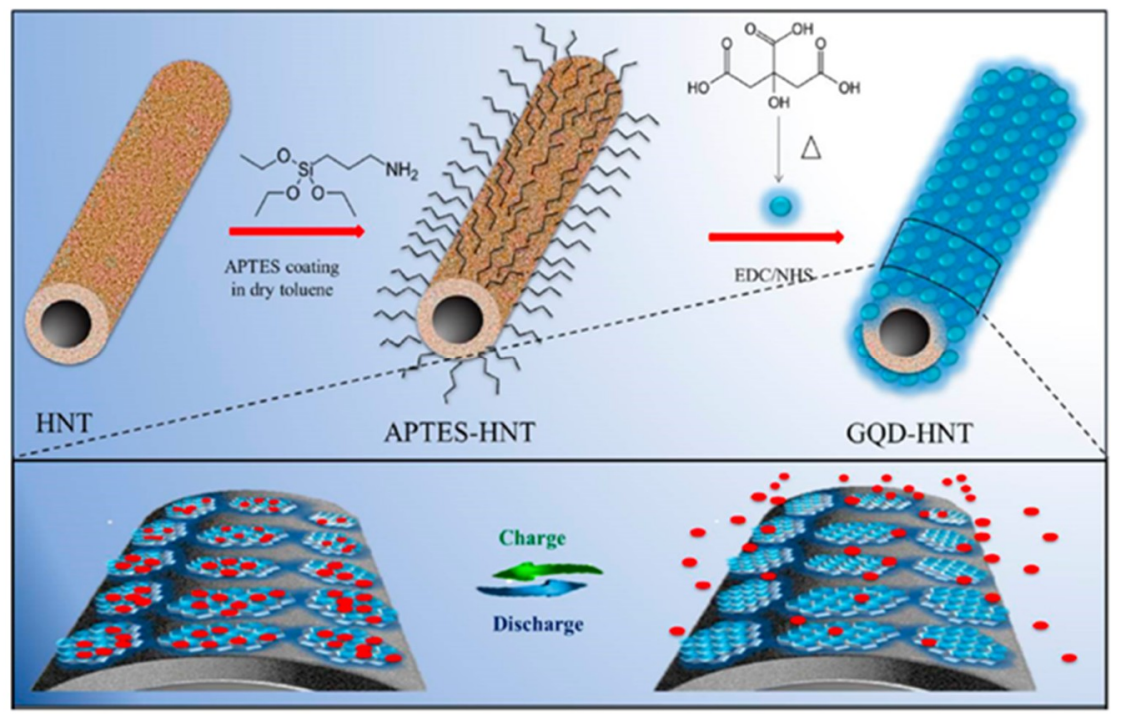

Figure 13. Synthesis of GQDs/HNTs hybrid for the fabrication of micro-supercapacitor electrode [241].

Table 3. Examples of MSCs involving the use of GQDs with their respective capacitive performance.

\begin{tabular}{ccc}
\hline Electrode Material & Specific Capacitance & References \\
\hline $\begin{array}{c}\text { Amine-functionalized single-crystalline GQDs } \\
\text { Nitrogen and oxygen co-doped GQDs/carbon } \\
\text { nanotubes/carbon cloth }\end{array}$ & $400-595 \mathrm{~F} \mathrm{~g}^{-1}$ & [243] \\
\hline GQDs/NiCo $2 \mathrm{~S}_{4}$ with hierarchical-like hollow nanostructure & $212 \mathrm{~F} \mathrm{~g}^{-1}$ & {$[244]$} \\
\hline GQDs/MnO 2 & $678.22 \mathrm{~F} \mathrm{~g}^{-1}$ & {$[245]$} \\
\hline Ultra-microporous carbons integrated GQDs & $1170 \mathrm{~F} \mathrm{~g}^{-1}$ & {$[246]$} \\
\hline GQDs/polypyrrole & $270 \mathrm{~F} \mathrm{~g}^{-1}$ & {$[247]$} \\
\hline Cobalt (II) chloride-GQDs & $485 \mathrm{~F} \mathrm{~g}^{-1}$ & {$[248]$} \\
\hline Fe (II)S-GQDs & $\sim 300 \mathrm{~F} \mathrm{~g}^{-1}$ & {$[249]$} \\
\hline Porous carbon nanosheets/GQDs & $476.2 \mathrm{~F} \mathrm{~g}^{-1}$ & {$[250]$} \\
\hline
\end{tabular}

\section{Conclusions}

GQDs are confirmed to be excellent imaging probes by numerous applications with their small sizes. After the first realization of their photoluminescence feature, studies were shaped towards the highly qualified, non-toxic, non-invasive, and target-oriented bio-imaging and therapy applications. It is possible to manufacture GQDs in greater amounts than the laboratory conditions by preparing industrial-scale productions, without dissipating any of their distinctive features that enable the bio-imaging. Moreover, the abundant carboxylic groups present in GQDs allows their functionalization with active biomolecules and are widely used for the therapy development and drug delivery. Various methods for the synthesis of GQDs have been updated day by day with increasing quality and efficiency. On the other hand, doping GQDs with diverse atoms endow unique attributes to these tiny particles. Hence, it is very likely and preferred that GQDs are holding an immense promise for a wide range of bio-imaging studies as well as commercialized applications. Moreover, as a potent electrode material for the fabrication of micro-supercapacitors, GQDs offer benefits for developing portable and highly efficient electronic tools owing to their quantum confinement and edge effects.

Author Contributions: Conceptualization, Z.A., Investigation, M.K., B.D.M., and N.V.S.; Resources, Z.A.; Writing, M.K., B.D.M., N.V.S., and Z.A.; Editing, Z.A.; Supervision, Z.A. All authors have read and agreed to the published version of the manuscript. 
Funding: This research received no external funding.

Conflicts of Interest: The authors declare no conflict of interest.

\section{References}

1. Wang, X.; Kalali, E.N.; Wan, J.-T.; Wang, D.-Y. Carbon-family materials for flame retardant polymeric materials. Prog. Polym. Sci. 2017, 69, 22-46. [CrossRef]

2. Aliofkhazraei, M.; Ali, N.; Milne, W.; Ozkan, C.; Mitura, S.; Gervasoni, J. Graphene science handbook: Applications and industrialization. In Graphene Science Handbook: Applications and Industrialization; CRC Press: Boca Raton, FL, USA, 2016; ISBN 9781466591332.

3. Allen, M.J.; Tung, V.C.; Kaner, R.B. Honeycomb carbon: A review of graphene. Chem. Rev. 2010, 110, $132-145$. [CrossRef]

4. Pace, N.R. The universal nature of biochemistry. Proc. Natl. Acad. Sci. USA 2001, 98, 805-808. [CrossRef]

5. Jonsson, A.L.; Roberts, M.A.J.; Kiappes, J.L.; Scott, K.A. Essential chemistry for biochemists. Essays Biochem. 2017, 61, 401-427. [CrossRef] [PubMed]

6. Pirzada, M.; Altintas, Z. Nanomaterials for healthcare biosensing applications. Sensors 2019, $19,5311$. [CrossRef] [PubMed]

7. Tian, P.; Tang, L.; Teng, K.S.; Lau, S.P. Graphene quantum dots from chemistry to applications. Mater. Today Chem. 2018, 10, 221-258. [CrossRef]

8. Li, M.; Chen, T.; Gooding, J.J.; Liu, J. Review of carbon and graphene quantum dots for sensing. ACS Sens. 2019, 4, 1732-1748. [CrossRef]

9. Hong, G.L.; Zhao, H.L.; Deng, H.H.; Yang, H.J.; Peng, H.P.; Liu, Y.H.; Chen, W. Fabrication of ultra-small monolayer graphene quantum dots by pyrolysis of trisodium citrate for fluorescent cell imaging. Int. J. Nanomed. 2018, 13, 4807-4815. [CrossRef]

10. Yan, C.; Hu, X.; Guan, P.; Hou, T.; Chen, P.; Wan, D.; Zhang, X.; Wang, J.; Wang, C. Highly biocompatible graphene quantum dots: Green synthesis, toxicity comparison and fluorescence imaging. J. Mater. Sci. 2020, 55, 1198-1215. [CrossRef]

11. Su, Z.; Shen, H.; Wang, H.; Wang, J.; Li, J.; Nienhaus, G.U.; Shang, L.; Wei, G. Motif-designed peptide nanofibers decorated with graphene quantum dots for simultaneous targeting and imaging of tumor cells. Adv. Funct. Mater. 2015, 25, 5472-5478. [CrossRef]

12. Abbas, A.; Tuti Mariana, L.; Phan, A.N. Biomass-waste derived graphene quantum dots and their applications. Carbon 2018, 140, 77-99. [CrossRef]

13. Feng, Q.; Cao, Q.; Li, M.; Liu, F.; Tang, N.; Du, Y. Synthesis and photoluminescence of fluorinated graphene quantum dots. Appl. Phys. Lett. 2013, 102, 013111. [CrossRef]

14. Sun, H.; Wu, L.; Wei, W.; Qu, X. Recent advances in graphene quantum dots for sensing. Mater. Today 2013, 16, 433-442. [CrossRef]

15. Zhu, S.; Song, Y.; Wang, J.; Wan, H.; Zhang, Y.; Ning, Y.; Yang, B. Photoluminescence mechanism in graphene quantum dots: Quantum confinement effect and surface/edge state. Nano Today 2017, 13, 10-14. [CrossRef]

16. Zhang, Z.; Zhang, J.; Chen, N.; Qu, L. Graphene quantum dots: An emerging material for energy-related applications and beyond. Energy Environ. Sci. 2012, 5, 8869-8890. [CrossRef]

17. Campuzano, S.; Yáñez-Sedeño, P.; Pingarrón, J.M. Carbon dots and graphene quantum dots in electrochemical biosensing. Nanomaterials 2019, 9, 634. [CrossRef]

18. Zhang, R.; Qi, S.; Jia, J.; Torre, B.; Zeng, H.; Wu, H.; Xu, X. Size and refinement edge-shape effects of graphene quantum dots on UV-visible absorption. J. Alloys Compd. 2015, 623, 186-191. [CrossRef]

19. Dervishi, E.; Ji, Z.; Htoon, H.; Sykora, M.; Doorn, S.K. Raman spectroscopy of bottom-up synthesized graphene quantum dots: Size and structure dependence. Nanoscale 2019, 11, 16571-16581. [CrossRef]

20. Qi, B.P.; Hu, H.; Bao, L.; Zhang, Z.L.; Tang, B.; Peng, Y.; Wang, B.S.; Pang, D.W. An efficient edge-functionalization method to tune the photoluminescence of graphene quantum dots. Nanoscale 2015, 7, 5969-5973. [CrossRef]

21. Savas, S.; Altintas, Z. Graphene quantum dots as nanozymes for electrochemical sensing of yersinia enterocolitica in milk and human serum. Materials 2019, 12, 2189. [CrossRef]

22. Tashkhourian, J.; Nami-Ana, S.F.; Shamsipur, M. Designing a modified electrode based on graphene quantum dot-chitosan application to electrochemical detection of epinephrine. J. Mol. Liq. 2018, 266, 548-556. [CrossRef] 
23. Wang, H.; Revia, R.; Wang, K.; Kant, R.J.; Mu, Q.; Gai, Z.; Hong, K.; Zhang, M. Paramagnetic properties of metal-free boron-doped graphene quantum dots and their application for safe magnetic resonance imaging. Adv. Mater. 2017, 29, 1605416. [CrossRef] [PubMed]

24. Santos, C.I.M.; Rodríguez-Pérez, L.; Gonçalves, G.; Pinto, S.N.; Melle-Franco, M.; Marques, P.A.A.P.; Faustino, M.A.F.; Herranz, M.Á.; Martin, N.; Neves, M.G.P.M.S.; et al. Novel hybrids based on graphene quantum dots covalently linked to glycol corroles for multiphoton bioimaging. Carbon N. Y. 2020, 166, 164-174. [CrossRef]

25. Qin, X.; Wang, Q.; Geng, L.; Shu, X.; Wang, Y. A “signal-on” photoelectrochemical aptasensor based on graphene quantum dots-sensitized $\mathrm{TiO}_{2}$ nanotube arrays for sensitive detection of chloramphenicol. Talanta 2019, 197, 28-35. [CrossRef] [PubMed]

26. Gao, X.; Zhang, B.; Zhang, Q.; Tang, Y.; Liu, X.; Li, J. The influence of combination mode on the structure and properties of graphene quantum dot-porphyrin composites. Colloids Surf. B Biointerfaces 2018, 172, 207-212. [CrossRef] [PubMed]

27. Huang, J.Y.; Zhao, L.; Lei, W.; Wen, W.; Wang, Y.J.; Bao, T.; Xiong, H.Y.; Zhang, X.H.; Wang, S.F. A high-sensitivity electrochemical aptasensor of carcinoembryonic antigen based on graphene quantum dots-ionic liquid-nafion nanomatrix and DNAzyme-assisted signal amplification strategy. Biosens. Bioelectron. 2018, 99, 28-33. [CrossRef]

28. Wang, L.; Wu, B.; Li, W.; Li, Z.; Zhan, J.; Geng, B.; Wang, S.; Pan, D.; Wu, M. Industrial production of ultra-stable sulfonated graphene quantum dots for Golgi apparatus imaging. J. Mater. Chem. B 2017, 5, 5355-5361. [CrossRef]

29. Wu, C.; Wang, C.; Han, T.; Zhou, X.; Guo, S.; Zhang, J. Insight into the cellular internalization and cytotoxicity of graphene quantum dots. Adv. Healthc. Mater. 2013, 2, 1613-1619. [CrossRef]

30. Kumawat, M.K.; Thakur, M.; Gurung, R.B.; Srivastava, R. Graphene quantum dots for cell proliferation, nucleus imaging, and photoluminescent sensing applications. Sci. Rep. 2017, 7, 1-16. [CrossRef]

31. Şenel, B.; Demir, N.; Büyükköroğlu, G.; Yıldız, M. Graphene quantum dots: Synthesis, characterization, cell viability, genotoxicity for biomedical applications. Saudi Pharm. J. 2019, 27, 846-858. [CrossRef]

32. Liu, X.; Na, W.; Liu, Q.; Su, X. A novel label-free fluorescent sensor for highly sensitive detection of bleomycin based on nitrogen-doped graphene quantum dots. Anal. Chim. Acta 2018, 1028, 45-49. [CrossRef] [PubMed]

33. Mansuriya, B.D.; Altintas, Z. Applications of graphene quantum dots in biomedical sensors. Sensors 2020, 20, 1072. [CrossRef] [PubMed]

34. Mansuriya, B.D.; Altintas, Z. Graphene quantum dot-based electrochemical immunosensors for biomedical applications. Materials 2019, 13, 96. [CrossRef] [PubMed]

35. Iannazzo, D.; Pistone, A.; Salamò, M.; Galvagno, S.; Romeo, R.; Giofré, S.V.; Branca, C.; Visalli, G.; Di Pietro, A. Graphene quantum dots for cancer targeted drug delivery. Int. J. Pharm. 2017, 518, 185-192. [CrossRef] [PubMed]

36. Shin, D.H.; Seo, S.W.; Kim, J.M.; Lee, H.S.; Choi, S.H. Graphene transparent conductive electrodes doped with graphene quantum dots-mixed silver nanowires for highly-flexible organic solar cells. J. Alloys Compd. 2018, 744, 1-6. [CrossRef]

37. Shen, D.; Zhang, W.; Xie, F.; Li, Y.; Abate, A.; Wei, M. Graphene quantum dots decorated $\mathrm{TiO}_{2}$ mesoporous film as an efficient electron transport layer for high-performance perovskite solar cells. J. Power Sources 2018, 402, 320-326. [CrossRef]

38. Kim, J.; Lee, B.; Kim, Y.J.; Hwang, S.W. Enhancement of dye-sensitized solar cells efficiency using graphene quantum dots as photoanode. Bull. Korean Chem. Soc. 2019, 40, 56-61. [CrossRef]

39. Li, Z.; Bu, F.; Wei, J.; Yao, W.; Wang, L.; Chen, Z.; Pan, D.; Wu, M. Boosting the energy storage densities of supercapacitors by incorporating $\mathrm{N}$-doped graphene quantum dots into cubic porous carbon. Nanoscale 2018, 10, 22871-22883. [CrossRef]

40. Liu, W.-W.; Feng, Y.-Q.; Yan, X.-B.; Chen, J.-T.; Xue, Q.-J. Superior micro-supercapacitors based on graphene quantum dots. Adv. Funct. Mater. 2013, 23, 4111-4122. [CrossRef]

41. Luo, J.; Wang, J.; Liu, S.; Wu, W.; Jia, T.; Yang, Z.; Mu, S.; Huang, Y. Graphene quantum dots encapsulated tremella-like $\mathrm{NiCO}_{2} \mathrm{O}_{4}$ for advanced asymmetric supercapacitors. Carbon N. Y. 2019, 146, 1-8. [CrossRef]

42. Monroe, J.D.; Belekov, E.; Er, A.O.; Smith, M.E. Anticancer photodynamic therapy properties of sulfur-doped graphene quantum dot and methylene blue preparations in MCF-7 breast cancer cell culture. Photochem. Photobiol. 2019, 95, 1473-1481. [CrossRef] [PubMed] 
43. Zeng, Z.; Chen, S.; Tan, T.T.Y.; Xiao, F.X. Graphene quantum dots (GQDs) and its derivatives for multifarious photocatalysis and photoelectrocatalysis. Catal. Today 2018, 315, 171-183. [CrossRef]

44. Zheng, X.T.; Ananthanarayanan, A.; Luo, K.Q.; Chen, P. Glowing graphene quantum dots and carbon dots: Properties, syntheses, and biological applications. Small 2015, 11, 1620-1636. [CrossRef]

45. Yue, S.; Tong, H.; Lu, L.; Tang, W.; Bai, W.; Jin, F.; Han, Q.; He, J.; Liu, J.; Zhang, X. Hierarchical $\mathrm{NiCO}_{2} \mathrm{O}_{4}$ nanosheets/nitrogen doped graphene/carbon nanotube film with ultrahigh capacitance and long cycle stability as a flexible binder-free electrode for supercapacitors. J. Mater. Chem. A 2017, 5, 689-698. [CrossRef]

46. Iannazzo, D.; Ziccarelli, I.; Pistone, A. Graphene quantum dots: Multifunctional nanoplatforms for anticancer therapy. J. Mater. Chem. B 2017, 5, 6471-6489. [CrossRef]

47. Agarwal, S.; Sadeghi, N.; Tyagi, I.; Gupta, V.K.; Fakhri, A. Adsorption of toxic carbamate pesticide oxamyl from liquid phase by newly synthesized and characterized graphene quantum dots nanomaterials. J. Colloid Interface Sci. 2016, 478, 430-438. [CrossRef]

48. Su, J.; Zhang, X.; Tong, X.; Wang, X.; Yang, P.; Yao, F.; Guo, R.; Yuan, C. Preparation of graphene quantum dots with high quantum yield by a facile one-step method and applications for cell imaging. Mater. Lett. 2020, 271, 127806. [CrossRef]

49. Li, L.; Wu, G.; Yang, G.; Peng, J.; Zhao, J.; Zhu, J.J. Focusing on luminescent graphene quantum dots: Current status and future perspectives. Nanoscale 2013, 5, 4015-4039. [CrossRef]

50. Shen, J.; Zhu, Y.; Yang, X.; Li, C. Graphene quantum dots: Emergent nanolights for bioimaging, sensors, catalysis and photovoltaic devices. Chem. Commun. 2012, 48, 3686-3699. [CrossRef]

51. Zhao, M. Direct synthesis of graphene quantum dots with different fluorescence properties by oxidation of graphene oxide using nitric acid. Appl. Sci. 2018, 8, 1303. [CrossRef]

52. Ma, C.B.; Zhu, Z.T.; Wang, H.X.; Huang, X.; Zhang, X.; Qi, X.; Zhang, H.L.; Zhu, Y.; Deng, X.; Peng, Y.; et al. A general solid-state synthesis of chemically-doped fluorescent graphene quantum dots for bioimaging and optoelectronic applications. Nanoscale 2015, 7, 10162-10169. [CrossRef] [PubMed]

53. Ji, Z.; Dervishi, E.; Doorn, S.K.; Sykora, M. Size-dependent electronic properties of uniform ensembles of strongly confined graphene quantum dots. J. Phys. Chem. Lett. 2019, 10, 953-959. [CrossRef]

54. Tang, L.; Ji, R.; Li, X.; Teng, K.S.; Lau, S.P. Size-dependent structural and optical characteristics of glucose-derived graphene quantum dots. Part. Part. Syst. Charact. 2013, 30, 523-531. [CrossRef]

55. Ye, R.; Xiang, C.; Lin, J.; Peng, Z.; Huang, K.; Yan, Z.; Cook, N.P.; Samuel, E.L.G.; Hwang, C.-C.; Ruan, G.; et al. Coal as an abundant source of graphene quantum dots. Nat. Commun. 2013, 4, 2943. [CrossRef] [PubMed]

56. Pan, D.; Zhang, J.; Li, Z.; Wu, M. Hydrothermal route for cutting graphene sheets into blue-luminescent graphene quantum dots. Adv. Mater. 2010, 22, 734-738. [CrossRef]

57. Sun, Y.; Wang, S.; Li, C.; Luo, P.; Tao, L.; Wei, Y.; Shi, G. Large scale preparation of graphene quantum dots from graphite with tunable fluorescence properties. Phys. Chem. Chem. Phys. 2013, 15, 9907-9913. [CrossRef]

58. Nilewski, L.; Mendoza, K.; Jalilov, A.S.; Berka, V.; Wu, G.; Sikkema, W.K.A.; Metzger, A.; Ye, R.; Zhang, R.; Luong, D.X.; et al. Highly oxidized graphene quantum dots from coal as efficient antioxidants. ACS Appl. Mater. Interfaces 2019, 11, 16815-16821. [CrossRef]

59. Ganjali, M.R.; Dourandish, Z.; Beitollahi, H.; Tajik, S.; Hajiaghababaei, L.; Larijani, B. Highly sensitive determination of theophylline based on graphene quantum dots modified electrode. Int. J. Electrochem. Sci. 2018, 13, 2448-2461. [CrossRef]

60. Kellici, S.; Acord, J.; Moore, K.E.; Power, N.P.; Middelkoop, V.; Morgan, D.J.; Heil, T.; Coppo, P.; Baragau, I.A.; Raston, C.L. Continuous hydrothermal flow synthesis of graphene quantum dots. React. Chem. Eng. 2018, 3, 949-958. [CrossRef]

61. Luo, Z.; Yang, D.; Yang, C.; Wu, X.; Hu, Y.; Zhang, Y.; Yuwen, L.; Yeow, E.K.L.; Weng, L.; Huang, W.; et al. Graphene quantum dots modified with adenine for efficient two-photon bioimaging and white light-activated antibacteria. Appl. Surf. Sci. 2018, 434, 155-162. [CrossRef]

62. Ping, Y.; Ruiyi, L.; Yongqiang, Y.; Zaijun, L.; Zhiguo, G.; Guangli, W.; Junkang, L. Pentaethylenehexamine and D-penicillamine co-functionalized graphene quantum dots for fluorescent detection of mercury(II) and glutathione and bioimaging. Spectrochim. Acta Part A Mol. Biomol. Spectrosc. 2018, 203, 139-146. [CrossRef] [PubMed]

63. Tan, X.; Li, Y.; Li, X.; Zhou, S.; Fan, L.; Yang, S. Electrochemical synthesis of small-sized red fluorescent graphene quantum dots as a bioimaging platform. Chem. Commun. 2015, 51, 2544-2546. [CrossRef] [PubMed] 
64. Liu, Y.; Zhou, S.; Fan, L.; Fan, H. Synthesis of red fluorescent graphene quantum dot-europium complex composites as a viable bioimaging platform. Microchim. Acta 2016, 183, 2605-2613. [CrossRef]

65. Dong, J.; Wang, K.; Sun, L.; Sun, B.; Yang, M.; Chen, H.; Wang, Y.; Sun, J.; Dong, L. Application of graphene quantum dots for simultaneous fluorescence imaging and tumor-targeted drug delivery. Sens. Actuators B Chem. 2018, 256, 616-623. [CrossRef]

66. Kumawat, M.K.; Srivastava, R.; Thakur, M.; Gurung, R.B. Graphene quantum dots from mangifera indica: Application in near-infrared bioimaging and intracellular nanothermometry. ACS Sustain. Chem. Eng. 2017, 5, 1382-1391. [CrossRef]

67. Lu, L.; Zhu, Y.; Shi, C.; Pei, Y.T. Large-scale synthesis of defect-selective graphene quantum dots by ultrasonic-assisted liquid-phase exfoliation. Carbon N. Y. 2016, 109, 373-383. [CrossRef]

68. Ahirwar, S.; Mallick, S.; Bahadur, D. Photodynamic therapy using graphene quantum dot derivatives. J. Solid State Chem. 2020, 282, 121107. [CrossRef]

69. Li, Z.; Wang, D.; Xu, M.; Wang, J.; Hu, X.; Anwar, S.; Tedesco, A.C.; Morais, P.C.; Bi, H. Fluorine-containing graphene quantum dots with a high singlet oxygen generation applied for photodynamic therapy. J. Mater. Chem. B 2020, 8, 2598-2606. [CrossRef]

70. Zhou, L.; Geng, J.; Liu, B. Graphene quantum dots from polycyclic aromatic hydrocarbon for bioimaging and sensing of Fe3+ and hydrogen peroxide. Part. Part. Syst. Charact. 2013, 30, 1086-1092. [CrossRef]

71. Lu, J.; Yan, M.; Ge, L.; Ge, S.; Wang, S.; Yan, J.; Yu, J. Electrochemiluminescence of blue-luminescent graphene quantum dots and its application in ultrasensitive aptasensor for adenosine triphosphate detection. Biosens. Bioelectron. 2013, 47, 271-277. [CrossRef]

72. Mehrdad-Vahdati, B.; Pourhashem, S.; Sedghi, M.; Vaezi, Z.; Shojaedin-Givi, B.; Rashidi, A.; Naderi-Manesh, H. A novel aspect of functionalized graphene quantum dots in cytotoxicity studies. Toxicol. In Vitro 2019, 61, 104649. [CrossRef] [PubMed]

73. Chandra, A.; Deshpande, S.; Shinde, D.B.; Pillai, V.K.; Singh, N. Mitigating the cytotoxicity of graphene quantum dots and enhancing their applications in bioimaging and drug delivery. ACS Macro Lett. 2014, 3, 1064-1068. [CrossRef]

74. Yuan, X.; Liu, Z.; Guo, Z.; Ji, Y.; Jin, M.; Wang, X. Cellular distribution and cytotoxicity of graphene quantum dots with different functional groups. Nanoscale Res. Lett. 2014, 9, 1-9. [CrossRef] [PubMed]

75. Liang, L.; Kong, Z.; Kang, Z.; Wang, H.; Zhang, L.; Shen, J.W. Theoretical evaluation on potential cytotoxicity of graphene quantum dots. ACS Biomater. Sci. Eng. 2016, 2, 1983-1991. [CrossRef]

76. Xie, Y.; Wan, B.; Yang, Y.; Cui, X.; Xin, Y.; Guo, L.H. Cytotoxicity and autophagy induction by graphene quantum dots with different functional groups. J. Environ. Sci. (China) 2019, 77, 198-209. [CrossRef]

77. Xu, S.; Li, F.; Su, B.; Hu, M.Z.; Gao, X.; Gao, C. Novel graphene quantum dots (GQDs)-incorporated thin film composite (TFC) membranes for forward osmosis (FO) desalination. Desalination 2019, 451, 219-230. [CrossRef]

78. Teymourinia, H.; Salavati-Niasari, M.; Amiri, O.; Yazdian, F. Application of green synthesized $\mathrm{TiO}_{2} / \mathrm{Sb}_{2} \mathrm{~S}_{3}$ /GQDs nanocomposite as high efficient antibacterial agent against E. coli and Staphylococcus aureus. Mater. Sci. Eng. C 2019, 99, 296-303. [CrossRef]

79. Mondal, M.K.; Mukherjee, S.; Joardar, N.; Roy, D.; Chowdhury, P.; Sinha Babu, S.P. Synthesis of smart graphene quantum dots: A benign biomaterial for prominent intracellular imaging and improvement of drug efficacy. Appl. Surf. Sci. 2019, 495, 143562. [CrossRef]

80. Hasanzadeh, M.; Shadjou, N. What are the reasons for low use of graphene quantum dots in immunosensing of cancer biomarkers? Mater. Sci. Eng. C 2017, 71, 1313-1326. [CrossRef]

81. Vázquez-Nakagawa, M.; Rodríguez-Pérez, L.; Herranz, M.A.; Martín, N. Chirality transfer from graphene quantum dot. Chem. Commun. 2016, 52, 665-668. [CrossRef]

82. Wu, Q.; Gao, J.; Chen, L.; Dong, S.; Li, H.; Qiu, H.; Zhao, L. Graphene quantum dots functionalized $\beta$-cyclodextrin and cellulose chiral stationary phases with enhanced enantioseparation performance. J. Chromatogr. A 2019, 1600, 209-218. [CrossRef]

83. Ou, J.; Zhu, Y.; Kong, Y.; Ma, J. Graphene quantum dots/B-cyclodextrin nanocomposites: A novel electrochemical chiral interface for tryptophan isomer recognition. Electrochem. Commun. 2015, 60, 60-63. [CrossRef]

84. Liu, Y.; Cao, N.; Gui, W.; Ma, Q. Nitrogen-doped graphene quantum dots-based fluorescence molecularly imprinted sensor for thiacloprid detection. Talanta 2018, 183, 339-344. [CrossRef] [PubMed] 
85. Kaur, M.; Kaur, M.; Sharma, V.K. Nitrogen-doped graphene and graphene quantum dots: A review onsynthesis and applications in energy, sensors and environment. Adv. Colloid Interface Sci. 2018, 259, 44-64. [CrossRef] [PubMed]

86. Huang, B.; He, J.; Bian, S.; Zhou, C.; Li, Z.; Xi, F.; Liu, J.; Dong, X. S-doped graphene quantum dots as nanophotocatalyst for visible light degradation. Chin. Chem. Lett. 2018, 29, 1698-1701. [CrossRef]

87. Bian, S.; Shen, C.; Hua, H.; Zhou, L.; Zhu, H.; Xi, F.; Liu, J.; Dong, X. One-pot synthesis of sulfur-doped graphene quantum dots as a novel fluorescent probe for highly selective and sensitive detection of lead(II). RSC Adv. 2016, 6, 69977-69983. [CrossRef]

88. Xia, C.; Hai, X.; Chen, X.W.; Wang, J.H. Simultaneously fabrication of free and solidified N, S-doped graphene quantum dots via a facile solvent-free synthesis route for fluorescent detection. Talanta 2017, 168, 269-278. [CrossRef]

89. Zhang, L.; Zhang, Z.Y.; Liang, R.P.; Li, Y.H.; Qiu, J.D. Boron-doped graphene quantum dots for selective glucose sensing based on the 'abnormal' aggregation-induced photoluminescence enhancement. Anal. Chem. 2014, 86, 4423-4430. [CrossRef]

90. Kang, G.S.; Lee, S.; Yeo, J.S.; Choi, E.S.; Lee, D.C.; Na, S.I.; Joh, H.I. Graphene quantum dots with nitrogen and oxygen derived from simultaneous reaction of solvent as exfoliant and dopant. Chem. Eng. J. 2019, 372, 624-630. [CrossRef]

91. Xue, Z.; Gao, H.; Li, X. A Green and lower-temperature synthesis of two-color fluorescent nitrogen doped graphene quantum dots. Dye. Pigment. 2018, 156, 379-385. [CrossRef]

92. Chen, J.; Than, A.; Li, N.; Ananthanarayanan, A.; Zheng, X.; Xi, F.; Liu, J.; Tian, J.; Chen, P. Sweet graphene quantum dots for imaging carbohydrate receptors in live cells. FlatChem 2017, 5, 25-32. [CrossRef]

93. Wang, Z.; Liu, Z.; Gu, B.; Gao, B.; Wang, T.; Zheng, X.; Wang, G.; Guo, Q.; Chen, D. Ultraviolet light-driven controllable doping of graphene quantum dots with tunable emission wavelength for fluorescence bio-imaging. Mater. Lett. 2020, 266, 127468. [CrossRef]

94. Luo, Y.; Li, M.; Sun, L.; Xu, Y.; Li, M.; Hu, G.; Tang, T.; Wen, J.; Li, X.; Zhang, J.; et al. High fluorescent sulfur regulating graphene quantum dots with tunable photoluminescence properties. J. Colloid Interface Sci. 2018, 529, 205-213. [CrossRef]

95. Mandal, B.; Sarkar, S. Exploring the electronic structure of graphene quantum dots. J. Nanopart. Res. 2012. [CrossRef]

96. Shen, J.; Zhu, Y.; Chen, C.; Yang, X.; Li, C. Facile preparation and upconversion luminescence of graphene quantum dots. Chem. Commun. 2011, 47, 2580-2582. [CrossRef] [PubMed]

97. Liu, M.L.; Yang, L.; Li, R.S.; Bin Chen, B.; Liu, H.; Huang, C.Z. Large-scale simultaneous synthesis of highly photoluminescent green amorphous carbon nanodots and yellow crystalline graphene quantum dots at room temperature. Green Chem. 2017, 19, 3611-3617. [CrossRef]

98. Jovanović, S.P.; Syrgiannis, Z.; Budimir, M.D.; Milivojević, D.D.; Jovanovic, D.J.; Pavlović, V.B.; Papan, J.M.; Bartenwerfer, M.; Mojsin, M.M.; Stevanović, M.J.; et al. Graphene quantum dots as singlet oxygen producer or radical quencher-The matter of functionalization with urea/thiourea. Mater. Sci. Eng. C 2020, 109, 110539. [CrossRef] [PubMed]

99. Drissi, L.B.; Ouarrad, H.; Ramadan, F.Z.; Fritzsche, W. Graphene and silicene quantum dots for nanomedical diagnostics. RSC Adv. 2019, 10, 801-811. [CrossRef]

100. Tabish, T.A.; Lin, L.; Ali, M.; Jabeen, F.; Ali, M.; Iqbal, R.; Horsell, D.W.; Winyard, P.G.; Zhang, S. Investigating the bioavailability of graphene quantum dots in lung tissues via fourier transform infrared spectroscopy. Interface Focus 2018, 8, 20170054. [CrossRef]

101. Tabish, T.A.; Zhang, S. Graphene Quantum Dots: Syntheses, Properties, and Biological Applications; Elsevier Ltd.: Amsterdam, The Netherlands, 2019; Volume 1-5, ISBN 9780128122952.

102. Wang, T.; Zhu, S.; Jiang, X. Toxicity mechanism of graphene oxide and nitrogen-doped graphene quantum dots in RBCs revealed by surface-enhanced infrared absorption spectroscopy. Toxicol. Res. 2015, 4, 885-894. [CrossRef]

103. Tabish, T.A.; Scotton, C.J.; Ferguson, D.C.J.; Lin, L.; Van Der Veen, A.; Lowry, S.; Ali, M.; Jabeen, F.; Winyard, P.G.; Zhang, S. Biocompatibility and toxicity of graphene quantum dots for potential application in photodynamic therapy. Nanomedicine 2018, 13, 1923-1937. [CrossRef] [PubMed]

104. Lee, B.C.; Lee, J.Y.; Kim, J.; Yoo, J.M.; Kang, I.; Kim, J.J.; Shin, N.; Kim, D.J.; Choi, S.W.; Kim, D.; et al. Graphene quantum dots as anti-inflammatory therapy for colitis. Sci. Adv. 2020, 6, 1-14. [CrossRef] [PubMed] 
105. Martín, C.; Jun, G.; Schurhammer, R.; Reina, G.; Chen, P.; Bianco, A.; Ménard-Moyon, C. Enzymatic degradation of graphene quantum dots by human peroxidases. Small 2019, 15, 1-7. [CrossRef] [PubMed]

106. Chong, Y.; Ma, Y.; Shen, H.; Tu, X.; Zhou, X.; Xu, J.; Dai, J.; Fan, S.; Zhang, Z. The in vitro and in vivo toxicity of graphene quantum dots. Biomaterials 2014, 35, 5041-5048. [CrossRef]

107. Fasbender, S.; Zimmermann, L.; Cadeddu, R.-P.; Luysberg, M.; Moll, B.; Janiak, C.; Heinzel, T.; Haas, R. The low toxicity of graphene quantum dots is reflected by marginal gene expression changes of primary human hematopoietic stem cells. Sci. Rep. 2019, 9, 12028. [CrossRef] [PubMed]

108. Tabish, T.A.; Zhang, S.; Winyard, P.G. Developing the next generation of graphene-based platforms for cancer therapeutics: The potential role of reactive oxygen species. Redox Biol. 2018, 15, 34-40. [CrossRef]

109. Wang, X.; Sun, X.; He, H.; Yang, H.; Lao, J.; Song, Y.; Xia, Y.; Xu, H.; Zhang, X.; Huang, F. A two-component active targeting theranostic agent based on graphene quantum dots. J. Mater. Chem. B 2015, 3, 3583-3590. [CrossRef]

110. Fan, Z.; Nie, Y.; Wei, Y.; Zhao, J.; Liao, X.; Zhang, J. Facile and large-scale synthesis of graphene quantum dots for selective targeting and imaging of cell nucleus and mitochondria. Mater. Sci. Eng. C 2019, 103, 109824. [CrossRef]

111. Nurunnabi, M.; Khatun, Z.; Huh, K.M.; Park, S.Y.; Lee, D.Y.; Cho, K.J.; Lee, Y.K. In vivo biodistribution and toxicology of carboxylated graphene quantum dots. ACS Nano 2013, 7, 6858-6867. [CrossRef]

112. Zhang, C.; Cui, Y.; Song, L.; Liu, X.; Hu, Z. Microwave assisted one-pot synthesis of graphene quantum dots as highly sensitive fluorescent probes for detection of iron ions and $\mathrm{pH}$ value. Talanta 2016, 150, 54-60. [CrossRef]

113. Malik, N.; Arfin, T.; Khan, A.U. Graphene Nanomaterials: Chemistry and Pharmaceutical Perspectives; Elsevier Inc.: Amsterdam, The Netherlands, 2019; ISBN 9780128165058.

114. Kikuchi, K. Design, synthesis and biological application of chemical probes for bio-imaging. Chem. Soc. Rev. 2010, 39, 2048-2053. [CrossRef] [PubMed]

115. Glasser, O.; Boveri, M. Rontgen, and the Discovery of X-rays. Nature 1890, 32, 511-512.

116. Rizzo, P.F.; Gould, E.S.; Lyden, J.P.; Asnis, S.E. Diagnosis of occult fractures about the hip. Magnetic resonance imaging compared with bone-scanning. J. Bone Jt. Surg. Ser. A 1993, 75, 395-401. [CrossRef] [PubMed]

117. Kuhl, C.K.; Schrading, S.; Bieling, H.B.; Wardelmann, E.; Leutner, C.C.; Koenig, R.; Kuhn, W.; Schild, H.H. MRI for diagnosis of pure ductal carcinoma in situ: A prospective observational study. Lancet 2007, 370, 485-492. [CrossRef]

118. Mahlknecht, P.; Hotter, A.; Hussl, A.; Esterhammer, R.; Schocke, M.; Seppi, K. Significance of MRI in diagnosis and differential diagnosis of parkinson's disease. Neurodegener. Dis. 2010, 7, 300-318. [CrossRef] [PubMed]

119. Nguyen, T.D.T.; Pitchaimani, A.; Ferrel, C.; Thakkar, R.; Aryal, S. Nano-confinement-driven enhanced magnetic relaxivity of SPIONs for targeted tumor bioimaging. Nanoscale 2018, 10, 284-294. [CrossRef]

120. Van Tam, T.; Choi, W.M. One-pot synthesis of highly fluorescent amino-functionalized graphene quantum dots for effectivae detection of copper ions. Curr. Appl. Phys. 2018, 18, 1255-1260.

121. Tang, L.; Ji, R.; Li, X.; Bai, G.; Liu, C.P.; Hao, J.; Lin, J.; Jiang, H.; Teng, K.S.; Yang, Z.; et al. Deep ultraviolet to near-infrared emission and photoresponse in layered n-doped graphene quantum dots. ACS Nano 2014, 8 , 6312-6320. [CrossRef]

122. Sharma, P.; Brown, S.; Walter, G.; Santra, S.; Moudgil, B. Nanoparticles for bioimaging. Adv. Colloid Interface Sci. 2006, 123-126, 471-485. [CrossRef]

123. Gao, X.; Yang, L.; Petros, J.A.; Marshall, F.F.; Simons, J.W.; Nie, S. In vivo molecular and cellular imaging with quantum dots. Curr. Opin. Biotechnol. 2005, 16, 63-72. [CrossRef]

124. Zhu, C.; Du, D.; Lin, Y. Graphene and graphene-like 2D materials for optical biosensing and bioimaging: A review. 2D Mater. 2015, 2, 32004. [CrossRef]

125. Nair, R.V.; Thomas, R.T.; Sankar, V.; Muhammad, H.; Dong, M.; Pillai, S. Rapid, Acid-Free Synthesis of High-Quality Graphene Quantum Dots for Aggregation Induced Sensing of Metal Ions and Bioimaging. ACS Omega 2017, 2, 8051-8061. [CrossRef] [PubMed]

126. Zhu, S.; Zhang, J.; Qiao, C.; Tang, S.; Li, Y.; Yuan, W.; Li, B.; Tian, L.; Liu, F.; Hu, R.; et al. Strongly green-photoluminescent graphene quantum dots for bioimaging applications. Chem. Commun. 2011, 47, 6858-6860. [CrossRef] [PubMed] 
127. Zhu, S.; Zhang, J.; Tang, S.; Qiao, C.; Wang, L.; Wang, H.; Liu, X.; Li, B.; Li, Y.; Yu, W.; et al. Surface chemistry routes to modulate the photoluminescence of graphene quantum dots: From fluorescence mechanism to up-conversion bioimaging applications. Adv. Funct. Mater. 2012, 22, 4732-4740. [CrossRef]

128. Sun, H.; Wu, L.; Gao, N.; Ren, J.; Qu, X. Improvement of photoluminescence of graphene quantum dots with a biocompatible photochemical reduction pathway and its bioimaging application. ACS Appl. Mater. Interfaces 2013, 5, 1174-1179. [CrossRef]

129. Qian, Z.; Ma, J.; Shan, X.; Shao, L.; Zhou, J.; Chen, J.; Feng, H. Surface functionalization of graphene quantum dots with small organic molecules from photoluminescence modulation to bioimaging applications: An experimental and theoretical investigation. RSC Adv. 2013, 3, 14571-14579. [CrossRef]

130. Hu, C.; Liu, Y.; Yang, Y.; Cui, J.; Huang, Z.; Wang, Y.; Yang, L.; Wang, H.; Xiao, Y.; Rong, J. One-step preparation of nitrogen-doped graphene quantum dots from oxidized debris of graphene oxide. J. Mater. Chem. B 2013, 1, 39-42. [CrossRef]

131. Kumar, V.; Singh, V.; Umrao, S.; Parashar, V.; Abraham, S.; Singh, A.K.; Nath, G.; Saxena, P.S.; Srivastava, A. Facile, rapid and upscaled synthesis of green luminescent functional graphene quantum dots for bioimaging. RSC Adv. 2014, 4, 21101-21107. [CrossRef]

132. Zhang, K.Y.; Yu, Q.; Wei, H.; Liu, S.; Zhao, Q.; Huang, W. Long-lived emissive probes for time-resolved photoluminescence bioimaging and biosensing. Chem. Rev. 2018, 118, 1770-1839. [CrossRef]

133. $\mathrm{Pu}, \mathrm{K}$. Biosenors and Bioimaging. ChemBioChem 2019, 20, 420-421. [CrossRef]

134. Wang, F.H.; Bae, K.; Huang, Z.W.; Xue, J.M. Two-photon graphene quantum dot modified $\mathrm{Gd}_{2} \mathrm{O}_{3}$ nanocomposites as a dual-mode MRI contrast agent and cell labelling agent. Nanoscale 2018, 10, 5642-5649. [CrossRef] [PubMed]

135. Theer, P.; Hasan, M.T.; Denk, W. Two-photon imaging to a depth of $1000 \mu \mathrm{m}$ in living brains by use of a $\mathrm{TiAl}_{2} \mathrm{O}_{3}$ regenerative amplifier. Opt. Lett. 2003, 28, 1022. [CrossRef] [PubMed]

136. Yao, S.; Belfield, K.D. Two-photon fluorescent probes for bioimaging. Eur. J. Org. Chem. 2012, 2012, $3199-3217$. [CrossRef]

137. Kim, H.M.; Cho, B.R. Small-molecule two-photon probes for bioimaging applications. Chem. Rev. 2015, 115, 5014-5055. [CrossRef] [PubMed]

138. Pan, L.; Sun, S.; Zhang, L.; Jiang, K.; Lin, H. Near-infrared emissive carbon dots for two-photon fluorescence bioimaging. Nanoscale 2016, 8, 17350-17356. [CrossRef]

139. Liu, Q.; Guo, B.; Rao, Z.; Zhang, B.; Gong, J.R. Strong two-photon-induced fluorescence from photostable, biocompatible nitrogen-doped graphene quantum dots for cellular and deep-tissue imaging. Nano Lett. 2013, 13, 2436-2441. [CrossRef]

140. Guo, R.; Zhou, S.; Li, Y.; Li, X.; Fan, L.; Voelcker, N.H. Rhodamine-functionalized graphene quantum dots for detection of $\mathrm{Fe}^{3+}$ in cancer stem cells. ACS Appl. Mater. Interfaces 2015, 7, 23958-23966. [CrossRef]

141. Zhu, X.; Zhang, Z.; Xue, Z.; Huang, C.; Shan, Y.; Liu, C.; Qin, X.; Yang, W.; Chen, X.; Wang, T. Understanding the selective detection of $\mathrm{Fe}^{3+}$ based on graphene quantum dots as fluorescent probes: The Ksp of a metal hydroxide-assisted mechanism. Anal. Chem. 2017, 89, 12054-12058. [CrossRef]

142. Sheng, L.; Huangfu, B.; Xu, Q.; Tian, W.; Li, Z.; Meng, A.; Tan, S. A highly selective and sensitive fluorescent probe for detecting $\mathrm{Cr}(\mathrm{VI})$ and cell imaging based on nitrogen-doped graphene quantum dots. J. Alloys Compd. 2020, 820, 153191. [CrossRef]

143. Wang, Z.; Chen, D.; Gu, B.; Gao, B.; Wang, T.; Guo, Q.; Wang, G. Biomass-derived nitrogen doped graphene quantum dots with color-tunable emission for sensing, fluorescence ink and multicolor cell imaging. Spectrochim. Acta Part A Mol. Biomol. Spectrosc. 2020, 227, 117671. [CrossRef]

144. Bilan, R.; Fleury, F.; Nabiev, I.; Sukhanova, A. Quantum dot surface chemistry and functionalization for cell targeting and imaging. Bioconjug. Chem. 2015, 26, 609-624. [CrossRef] [PubMed]

145. Li, Z.; Huang, P.; He, R.; Lin, J.; Yang, S.; Zhang, X.; Ren, Q.; Cui, D. Aptamer-conjugated dendrimer-modified quantum dots for cancer cell targeting and imaging. Mater. Lett. 2010, 64, 375-378. [CrossRef]

146. Park, J.-H.; von Maltzahn, G.; Zhang, L.; Schwartz, M.P.; Ruoslahti, E.; Bhatia, S.N.; Sailor, M.J. Magnetic Iron Oxide Nanoworms for Tumor Targeting and Imaging. Adv. Mater. 2008, 20, 1630-1635. [CrossRef] [PubMed]

147. Gao, T.; Wang, X.; Yang, L.Y.; He, H.; Ba, X.X.; Zhao, J.; Jiang, F.L.; Liu, Y. Red, Yellow, and Blue Luminescence by Graphene Quantum Dots: Syntheses, Mechanism, and Cellular Imaging. ACS Appl. Mater. Interfaces 2017, 9, 24846-24856. [CrossRef] [PubMed] 
148. Fang, J.; Nakamura, H.; Maeda, H. The EPR effect: Unique features of tumor blood vessels for drug delivery, factors involved, and limitations and augmentation of the effect. Adv. Drug Deliv. Rev. 2011, 63, 136-151. [CrossRef]

149. Zhang, J.; Zhao, X.; Xian, M.; Dong, C.; Shuang, S. Folic acid-conjugated green luminescent carbon dots as a nanoprobe for identifying folate receptor-positive cancer cells. Talanta 2018, 183, 39-47. [CrossRef]

150. John, A.A.; Kumar Jaganathan, S.; Ayyar, M.; Krishnasamy, N.P.; Rajasekar, R.; Supriyanto, E. Folic acid decorated chitosan nanoparticles and its derivatives for the delivery of drugs and genes to cancer cells. Curr. Sci. 2017, 113. [CrossRef]

151. Zhao, X.; Zhang, J.; Shi, L.; Xian, M.; Dong, C.; Shuang, S. Folic acid-conjugated carbon dots as green fluorescent probes based on cellular targeting imaging for recognizing cancer cells. RSC Adv. 2017, 7, 42159-42167. [CrossRef]

152. Wang, Y.; Song, H.; Wang, G.; Yang, X.; Wang, J.; Wei, H. ${ }^{131}$ I-labeled PEG and folic acid co-functionalized graphene quantum dots for tumor-targeted imaging. J. Radioanal. Nucl. Chem. 2019, 319, 1119-1125. [CrossRef]

153. Suryawanshi, A.; Biswal, M.; Mhamane, D.; Gokhale, R.; Patil, S.; Guin, D.; Ogale, S. Large scale synthesis of graphene quantum dots (GQDs) from waste biomass and their use as an efficient and selective photoluminescence on-off-on probe for $\mathrm{Ag}^{+}$ions. Nanoscale 2014, 6, 11664-11670. [CrossRef]

154. Shin, Y.; Lee, J.; Yang, J.; Park, J.; Lee, K.; Kim, S.; Park, Y.; Lee, H. Mass production of graphene quantum dots by one-pot synthesis directly from graphite in high yield. Small 2014, 10, 866-870. [CrossRef] [PubMed]

155. Deng, J.; Lu, Q.; Li, H.; Zhang, Y.; Yao, S. Large scale preparation of graphene quantum dots from graphite oxide in pure water via one-step electrochemical tailoring. RSC Adv. 2015, 5, 29704-29707. [CrossRef]

156. Wang, Z.; Yu, J.; Zhang, X.; Li, N.; Liu, B.; Li, Y.; Wang, Y.; Wang, W.; Li, Y.; Zhang, L.; et al. Large-scale and controllable synthesis of graphene quantum dots from rice husk biomass: A comprehensive utilization strategy. ACS Appl. Mater. Interfaces 2016, 8, 1434-1439. [CrossRef] [PubMed]

157. Bansal, S.; Singh, J.; Kumari, U.; Kaur, I.P.; Barnwal, R.P.; Kumar, R.; Singh, S.; Singh, G.; Chatterjee, M. Development of biosurfactant-based graphene quantum dot conjugate as a novel and fluorescent theranostic tool for cancer. Int. J. Nanomed. 2019, 14, 809-818. [CrossRef] [PubMed]

158. Wang, X.; Sun, X.; Lao, J.; He, H.; Cheng, T.; Wang, M.; Wang, S.; Huang, F. Multifunctional graphene quantum dots for simultaneous targeted cellular imaging and drug delivery. Colloids Surf. B Biointerfaces 2014, 122, 638-644. [CrossRef]

159. Ge, J.; Lan, M.; Zhou, B.; Liu, W.; Guo, L.; Wang, H.; Jia, Q.; Niu, G.; Huang, X.; Zhou, H.; et al. A graphene quantum dot photodynamic therapy agent with high singlet oxygen generation. Nat. Commun. 2014, 5, 1-8. [CrossRef]

160. Chong, Y.; Ge, C.; Fang, G.; Tian, X.; Ma, X.; Wen, T.; Wamer, W.G.; Chen, C.; Chai, Z.; Yin, J.J. Crossover between anti- and pro-oxidant activities of graphene quantum dots in the absence or presence of light. ACS Nano 2016, 10, 8690-8699. [CrossRef]

161. Wen, H.; Jung, H.; Li, X. Drug delivery approaches in addressing clinical pharmacology-related issues: Opportunities and challenges. AAPS J. 2015, 17, 1327-1340. [CrossRef]

162. Iannazzo, D.; Pistone, A.; Celesti, C.; Triolo, C.; Patané, S.; Giofré, S.V.; Romeo, R.; Ziccarelli, I.; Mancuso, R.; Gabriele, B.; et al. A smart nanovector for cancer targeted drug delivery based on graphene quantum dots. Nanomaterials 2019, 9, 282. [CrossRef]

163. Ud-Din, F.; Aman, W.; Ullah, I.; Qureshi, O.S.; Mustapha, O.; Shafique, S.; Zeb, A. Effective use of nanocarriers as drug delivery systems for the treatment of selected tumors. Int. J. Nanomed. 2017, 12, 7291-7309. [CrossRef]

164. Kumar, V.; Palazzolo, S.; Bayda, S.; Corona, G.; Toffoli, G.; Rizzolio, F. DNA nanotechnology for cancer therapy. Theranostics 2016, 6, 710-725. [CrossRef] [PubMed]

165. Qiu, J.; Zhang, R.; Li, J.; Sang, Y.; Tang, W.; Gil, P.R.; Liu, H. Fluorescent graphene quantum dots as traceable, pH-sensitive drug delivery systems. Int. J. Nanomed. 2015, 10, 6709-6724.

166. Wang, C.; Wu, C.; Zhou, X.; Han, T.; Xin, X.; Wu, J.; Zhang, J.; Guo, S. Enhancing cell nucleus accumulation and dna cleavage activity of anti-cancer drug via graphene quantum dots. Sci. Rep. 2013, 3, 1-8. [CrossRef] [PubMed]

167. Zhou, X.; Zhang, Y.; Wang, C.; Wu, X.; Yang, Y.; Zheng, B.; Wu, H.; Guo, S.; Zhang, J. Photo-Fenton reaction of graphene oxide: A new strategy to prepare graphene quantum dots for DNA cleavage. ACS Nano 2012,6, 6592-6599. [CrossRef]

168. Finder, V.H.; Glockshuber, R. Amyloid- $\beta$ aggregation. Neurodegener. Dis. 2007, 4, 13-27. [CrossRef] 
169. Fink, A.L. The aggregation and fibrillation of alfa synuclein. Acc. Chem. Res. 2006, 39, 628-634. [CrossRef]

170. Fowler, D.M.; Koulov, A.V.; Balch, W.E.; Kelly, J.W. Functional amyloid-From bacteria to humans. Trends Biochem. Sci. 2007, 32, 217-224. [CrossRef]

171. Friedland, R.P.; Chapman, M.R. The role of microbial amyloid in neurodegeneration. PLoS Pathog. 2017, 13, e1006654. [CrossRef]

172. Romero, D.; Aguilar, C.; Losick, R.; Kolter, R. Amyloid fibers provide structural integrity to Bacillus subtilis biofilms. Proc. Natl. Acad. Sci. USA 2010, 107, 2230-2234. [CrossRef]

173. Wang, Y.; Kadiyala, U.; Qu, Z.; Elvati, P.; Altheim, C.; Kotov, N.A.; Violi, A.; Vanepps, J.S. Anti-biofilm activity of graphene quantum dots via self-assembly with bacterial amyloid proteins. ACS Nano 2019, 13, 4278-4289. [CrossRef]

174. Wang, C.; Zhang, M.; Mao, X.; Yu, Y.; Wang, C.X.; Yang, Y.L. Nanomaterials for reducing amyloid cytotoxicity. Adv. Mater. 2013, 25, 3780-3801.

175. Ke, P.C.; Pilkington, E.H.; Sun, Y.; Javed, I.; Kakinen, A.; Peng, G.; Ding, F.; Davis, T.P. Mitigation of Amyloidosis with Nanomaterials. Adv. Mater. 2020, 32, 1901690. [CrossRef] [PubMed]

176. Goedert, M.; Spillantini, M.G. A century of Alzheimer's disease. Science 2006, 314, 777-781. [CrossRef] [PubMed]

177. Hardy, J.; Selokoe, D. The amyloid hypothesis of Alzheimer's disease. Amyloid Int. J. Exp. Clin. Investig. 2002, 297, 353-357. [CrossRef]

178. Takahashi, T.; Mihara, H. Peptide and protein mimetics inhibiting amyloid $\beta$-peptide aggregation. Acc. Chem. Res. 2008, 41, 1309-1318. [CrossRef]

179. Kim, D.; Yoo, J.M.; Hwang, H.; Lee, J.; Lee, S.H.; Yun, S.P.; Park, M.J.; Lee, M.J.; Choi, S.; Kwon, S.H.; et al. Graphene quantum dots prevent $\alpha$-synucleinopathy in Parkinson's disease. Nat. Nanotechnol. 2018, 13, 812-818. [CrossRef]

180. Liu, Y.; Xu, L.P.; Dai, W.; Dong, H.; Wen, Y.; Zhang, X. Graphene quantum dots for the inhibition of $\beta$ amyloid aggregation. Nanoscale 2015, 7, 19060-19065. [CrossRef]

181. Faridi, A.; Sun, Y.; Mortimer, M.; Aranha, R.R.; Nandakumar, A.; Li, Y.; Javed, I.; Kakinen, A.; Fan, Q.; Purcell, A.W.; et al. Graphene quantum dots rescue protein dysregulation of pancreatic $\beta$-cells exposed to human islet amyloid polypeptide. Nano Res. 2019, 12, 2827-2834. [CrossRef]

182. Wang, M.; Sun, Y.; Cao, X.; Peng, G.; Javed, I.; Kakinen, A.; Davis, T.P.; Lin, S.; Liu, J.; Ding, F.; et al. Graphene quantum dots against human IAPP aggregation and toxicity: In vivo. Nanoscale 2018, 10, 19995-20006. [CrossRef]

183. Chapman, M.R.; Robinson, L.S.; Pinkner, J.S.; Roth, R.; Heuser, J.; Hammar, M.; Normark, S.; Hultgren, S.J. Role of Escherichia coli curli operons in directing amyloid fiber formation. Science 2002, 295, 851-855. [CrossRef]

184. Cheng, L.; Yang, K.; Li, Y.; Zeng, X.; Shao, M.; Lee, S.T.; Liu, Z. Multifunctional nanoparticles for upconversion luminescence/MR multimodal imaging and magnetically targeted photothermal therapy. Biomaterials 2012, 33, 2215-2222. [CrossRef] [PubMed]

185. Eda, G.; Lin, Y.Y.; Mattevi, C.; Yamaguchi, H.; Chen, H.A.; Chen, I.S.; Chen, C.W.; Chhowalla, M. Blue photoluminescence from chemically derived graphene oxide. Adv. Mater. 2010, 22, 505-509. [CrossRef] [PubMed]

186. Li, S.; Zhou, S.; Li, Y.; Li, X.; Zhu, J.; Fan, L.; Yang, S. Exceptionally high payload of the IR780 iodide on folic acid-functionalized graphene quantum dots for targeted photothermal therapy. ACS Appl. Mater. Interfaces 2017, 9, 22332-22341. [CrossRef]

187. Lucky, S.S.; Soo, K.C.; Zhang, Y. Nanoparticles in photodynamic therapy. Chem. Rev. 2015, 115, 1990-2042. [CrossRef] [PubMed]

188. Kuo, W.S.; Chen, H.H.; Chen, S.Y.; Chang, C.Y.; Chen, P.C.; Hou, Y.I.; Shao, Y.T.; Kao, H.F.; Lilian Hsu, C.L.; Chen, Y.C.; et al. Graphene quantum dots with nitrogen-doped content dependence for highly efficient dual-modality photodynamic antimicrobial therapy and bioimaging. Biomaterials 2017, 120, 185-194. [CrossRef]

189. Ristic, B.Z.; Milenkovic, M.M.; Dakic, I.R.; Todorovic-Markovic, B.M.; Milosavljevic, M.S.; Budimir, M.D.; Paunovic, V.G.; Dramicanin, M.D.; Markovic, Z.M.; Trajkovic, V.S. Photodynamic antibacterial effect of graphene quantum dots. Biomaterials 2014, 35, 4428-4435. [CrossRef]

190. Zhou, Z.; Song, J.; Nie, L.; Chen, X. Reactive oxygen species generating systems meeting challenges of photodynamic cancer therapy. Chem. Soc. Rev. 2016, 45, 6597-6626. [CrossRef]

191. Schroeder, K.L.; Goreham, R.V.; Nann, T. Graphene quantum dots for theranostics and bioimaging. Pharm. Res. 2016, 33, 2337-2357. [CrossRef] 
192. Younis, M.R.; He, G.; Lin, J.; Huang, P. Recent advances on graphene quantum dots for bioimaging applications. Front. Chem. 2020, 8, 1-25. [CrossRef]

193. Zhou, Y.; Sun, H.; Wang, F.; Ren, J.; Qu, X. How functional groups to influence ROS generation and cytotoxicity of graphene quantum dots. Chem. Commun. 2017, 53, 10588-10591. [CrossRef]

194. Zhang, D.; Wen, L.; Huang, R.; Wang, H.; Hu, X.; Xing, D. Mitochondrial specific photodynamic therapy by rare-earth nanoparticles mediated near-infrared graphene quantum dots. Biomaterials 2018, 153, 14-26. [CrossRef]

195. Mei, L.; Cao, F.; Zhang, L.; Xu, J.; Xu, Z.; Yu, Y.; Zhang, X.; Shi, Y.; Li, X.; Cheng, K.; et al. Ag-conjugated graphene quantum dots with blue light-enhanced singlet oxygen generation for ternary-mode highly-efficient antimicrobial therapy. J. Mater. Chem. B 2020, 8, 1371-1382.

196. Kholikov, K.; Ilhom, S.; Sajjad, M.; Smith, M.E.; Monroe, J.D.; San, O.; Er, A.O. Improved singlet oxygen generation and antimicrobial activity of sulphur-doped graphene quantum dots coupled with methylene blue for photodynamic therapy applications. Photodiagnosis Photodyn. Ther. 2018, 24, 7-14. [CrossRef] [PubMed]

197. Lu, X.; Zhai, T.; Zhang, X.; Shen, Y.; Yuan, L.; Hu, B.; Gong, L.; Chen, J.; Gao, Y.; Zhou, J.; et al. $\mathrm{WO}_{3}$-x@Au@ $\mathrm{MnO}_{2}$ core-shell nanowires on carbon fabric for high-performance flexible supercapacitors. Adv. Mater. 2012, 24, 938-944. [CrossRef] [PubMed]

198. Ding, Y.L.; Wen, Y.; Wu, C.; Van Aken, P.A.; Maier, J.; Yu, Y. 3D V $6 \mathrm{O}_{13}$ nanotextiles assembled from interconnected nanogrooves as cathode materials for high-energy lithium ion batteries. Nano Lett. 2015, 15, 1388-1394. [CrossRef]

199. Lu, X.; Yu, M.; Wang, G.; Tong, Y.; Li, Y. Flexible solid-state supercapacitors: Design, fabrication and applications. Energy Environ. Sci. 2014, 7, 2160-2181. [CrossRef]

200. Stoller, M.D.; Park, S.; Yanwu, Z.; An, J.; Ruoff, R.S. Graphene-based ultracapacitors. Nano Lett. 2008, 8, 3498-3502. [CrossRef]

201. Winter, M.; Brodd, R.J. What are batteries, fuel cells, and supercapacitors? Chem. Rev. 2004, 104, 4245-4269. [CrossRef]

202. Cong, H.P.; Ren, X.C.; Wang, P.; Yu, S.H. Flexible graphene-polyaniline composite paper for high-performance supercapacitor. Energy Environ. Sci. 2013, 6, 1185-1191. [CrossRef]

203. Huang, X.; Qi, X.; Boey, F.; Zhang, H. Graphene-based composites. Chem. Soc. Rev. 2012, 41, 666-686. [CrossRef]

204. Liu, C.; Li, F.; Lai-Peng, M.; Cheng, H.M. Advanced materials for energy storage. Adv. Mater. 2010, $22,28-62$. [CrossRef] [PubMed]

205. Khaleed, A.A.; Bello, A.; Dangbegnon, J.K.; Madito, M.J.; Olaniyan, O.; Barzegar, F.; Makgopa, K.; Oyedotun, K.O.; Mwakikunga, B.W.; Ray, S.C.; et al. Solvothermal synthesis of surfactant free spherical nickel hydroxide/graphene oxide composite for supercapacitor application. J. Alloys Compd. 2017, 721, 80-91. [CrossRef]

206. Yang, W.; Yang, W.; Kong, L.; Song, A.; Qin, X. Facile synthesis of nitrogen-doped porous carbon for high-performance supercapacitors. RSC Adv. 2017, 7, 55257-55263. [CrossRef]

207. Qiu, Z.; He, D.; Wang, Y.; Zhao, X.; Zhao, W.; Wu, H. High performance asymmetric supercapacitors with ultrahigh energy density based on hierarchical carbon nanotubes@NiO core-shell nanosheets and defect-introduced graphene sheets with hole structure. RSC Adv. 2017, 7, 7843-7856. [CrossRef]

208. Liu, M.; Gan, L.; Xiong, W.; Xu, Z.; Zhu, D.; Chen, L. Development of $\mathrm{MnO}_{2}$ /porous carbon microspheres with a partially graphitic structure for high performance supercapacitor electrodes. J. Mater. Chem. A 2014, 2, 2555-2562. [CrossRef]

209. Li, Z.; Wei, J.; Ren, J.; Wu, X.; Wang, L.; Pan, D.; Wu, M. Hierarchical construction of high-performance all-carbon flexible fiber supercapacitors with graphene hydrogel and nitrogen-doped graphene quantum dots. Carbon N. Y. 2019, 154, 410-419. [CrossRef]

210. Lee, K.; Lee, H.; Shin, Y.; Yoon, Y.; Kim, D.; Lee, H. Highly transparent and flexible supercapacitors using graphene-graphene quantum dots chelate. Nano Energy 2016, 26, 746-754. [CrossRef]

211. Tjandra, R.; Liu, W.; Zhang, M.; Yu, A. All-carbon flexible supercapacitors based on electrophoretic deposition of graphene quantum dots on carbon cloth. J. Power Sources 2019, 438, 227009. [CrossRef]

212. Zhou, Q.; Li, Y.; Huang, L.; Li, C.; Shi, G. Three-dimensional porous graphene/polyaniline composites for high-rate electrochemical capacitors. J. Mater. Chem. A 2014, 2, 17489-17494. [CrossRef] 
213. Zhang, L.; Zhao, X.S. Carbon-based materials as supercapacitor electrodes. Chem. Soc. Rev. 2009, 38, 2520-2531. [CrossRef]

214. Jiang, J.; Li, Y.; Liu, J.; Huang, X.; Yuan, C.; Lou, X.W. Recent advances in metal oxide-based electrode architecture design for electrochemical energy storage. Adv. Mater. 2012, 24, 5166-5180. [CrossRef] [PubMed]

215. Li, X.; Yang, L.; Lei, Y.; Gu, L.; Xiao, D. Microwave-assisted chemical-vapor-induced in situ polymerization of polyaniline nanofibers on graphite electrode for high-performance supercapacitor. ACS Appl. Mater. Interfaces 2014, 6, 19978-19989. [CrossRef]

216. Zang, X.; Li, X.; Zhu, M.; Li, X.; Zhen, Z.; He, Y.; Wang, K.; Wei, J.; Kang, F.; Zhu, H. Graphene/polyaniline woven fabric composite films as flexible supercapacitor electrodes. Nanoscale 2015, 7, 7318-7322. [CrossRef] [PubMed]

217. Zhang, F.; Liu, T.; Li, M.; Yu, M.; Luo, Y.; Tong, Y.; Li, Y. Multiscale pore network boosts capacitance of carbon electrodes for ultrafast charging. Nano Lett. 2017, 17, 3097-3104. [CrossRef] [PubMed]

218. Wang, X.; Zhang, Y.; Zhi, C.; Wang, X.; Tang, D.; Xu, Y.; Weng, Q.; Jiang, X.; Mitome, M.; Golberg, D.; et al. Three-dimensional strutted graphene grown by substrate-free sugar blowing for high-power-density supercapacitors. Nat. Commun. 2013, 4, 1-8. [CrossRef] [PubMed]

219. Zhang, L.; Zhang, F.; Yang, X.; Long, G.; Wu, Y.; Zhang, T.; Leng, K.; Huang, Y.; Ma, Y.; Yu, A.; et al. Porous 3D graphene-based bulk materials with exceptional high surface area and excellent conductivity for supercapacitors. Sci. Rep. 2013, 3, 1-9. [CrossRef]

220. Li, Y.; Li, Z.; Shen, P.K. Simultaneous formation of ultrahigh surface area and three-dimensional hierarchical porous graphene-like networks for fast and highly stable supercapacitors. Adv. Mater. 2013, 25, 2474-2480. [CrossRef]

221. Feng, J.X.; Xu, H.; Ye, S.H.; Ouyang, G.; Tong, Y.X.; Li, G.R. Silica-polypyrrole hybrids as high-performance metal-free electrocatalysts for the hydrogen evolution reaction in neutral media. Angew. Chem. Int. Ed. 2017, 56, 8120-8124. [CrossRef]

222. Jeon, J.W.; Han, J.H.; Kim, S.K.; Kim, D.G.; Kim, Y.S.; Suh, D.H.; Hong, Y.T.; Kim, T.H.; Kim, B.G. Intrinsically microporous polymer-based hierarchical nanostructuring of electrodes: Via nonsolvent-induced phase separation for high-performance supercapacitors. J. Mater. Chem. A 2018, 6, 8909-8915. [CrossRef]

223. Hsieh, W.; Horng, T.L.A.; Huang, H.C.; Teng, H. Facile simulation of carbon with wide pore size distribution for electric double-layer capacitance based on Helmholtz models. J. Mater. Chem. A 2015, 3, 16535-16543. [CrossRef]

224. Yu, M.; Zhang, Y.; Zeng, Y.; Balogun, M.S.; Mai, K.; Zhang, Z.; Lu, X.; Tong, Y. Water surface assisted synthesis of large-scale carbon nanotube film for high-performance and stretchable supercapacitors. Adv. Mater. 2014, 26, 4724-4729. [CrossRef] [PubMed]

225. Shen, Y.; Qu, T.; Xiang, K.; Zhang, Y.; Tian, Z.; Xie, M.; Guo, X. Porous carbon nanosheets with abundant oxygen functionalities derived from phoenix seeds for high-performance supercapacitor. ChemistrySelect 2017, 2, 10704-10708. [CrossRef]

226. Shearer, C.J.; Cherevan, A.; Eder, D. Application and future challenges of functional nanocarbon hybrids. Adv. Mater. 2014, 26, 2295-2318. [CrossRef] [PubMed]

227. Liu, Z.A.; Tao, Y.; Song, X.Z.; Bao, M.; Tan, Z. A three dimensional N-doped graphene/CNTs/AC hybrid material for high-performance supercapacitors. RSC Adv. 2017, 7, 6664-6670. [CrossRef]

228. Wang, S.; Liu, N.; Su, J.; Li, L.; Long, F.; Zou, Z.; Jiang, X.; Gao, Y. Highly stretchable and self-healable supercapacitor with reduced graphene oxide based fiber springs. ACS Nano 2017, 11, 2066-2074. [CrossRef]

229. Li, X.; Rui, M.; Song, J.; Shen, Z.; Zeng, H. Carbon and graphene quantum dots for optoelectronic and energy devices: A review. Adv. Funct. Mater. 2015, 25, 4929-4947. [CrossRef]

230. Fan, Z.; Zhou, S.; Garcia, C.; Fan, L.; Zhou, J. PH-Responsive fluorescent graphene quantum dots for fluorescence-guided cancer surgery and diagnosis. Nanoscale 2017, 9, 4928-4933. [CrossRef]

231. Liu, W.W.; Yan, X.; Xue, Q.J. Multilayer hybrid films consisting of alternating graphene and titanium dioxide for high-performance supercapacitors. J. Mater. Chem. C 2013, 1, 1413-1422. [CrossRef]

232. Liu, W.W.; Yan, X.; Lang, J.W.; Peng, C.; Xue, Q.J. Flexible and conductive nanocomposite electrode based on graphene sheets and cotton cloth for supercapacitor. J. Mater. Chem. 2012, 22, 17245-17253. [CrossRef]

233. Hu, Y.; Zhao, Y.; Lu, G.; Chen, N.; Zhang, Z.; Li, H.; Shao, H.; Qu, L. Graphene quantum dots-carbon nanotube hybrid arrays for supercapacitors. Nanotechnology 2013, 24, 195401. [CrossRef] 
234. Chen, Q.; Hu, Y.; Hu, C.; Cheng, H.; Zhang, Z.; Shao, H.; Qu, L. Graphene quantum dots-three-dimensional graphene composites for high-performance supercapacitors. Phys. Chem. Chem. Phys. 2014, 16, 19307-19313. [CrossRef] [PubMed]

235. Li, Z.; Liu, X.; Wang, L.; Bu, F.; Wei, J.; Pan, D.; Wu, M. Hierarchical 3D all-carbon composite structure modified with n-doped graphene quantum dots for high-performance flexible supercapacitors. Small 2018, 14, 1-11. [CrossRef] [PubMed]

236. Luo, P.; Guan, X.; Yu, Y.; Li, X.; Yan, F. Hydrothermal synthesis of graphene quantum dots supported on three-dimensional graphene for supercapacitors. Nanomaterials 2019, 9, 201. [CrossRef]

237. Ouyang, Z.; Lei, Y.; Chen, Y.; Zhang, Z.; Jiang, Z.; Hu, J.; Lin, Y. Preparation and specific capacitance properties of sulfur, nitrogen co-doped graphene quantum dots. Nanoscale Res. Lett. 2019, 14, 1-9. [CrossRef] [PubMed]

238. Mondal, S.; Rana, U.; Malik, S. Graphene quantum dot-doped polyaniline nanofiber as high performance supercapacitor electrode materials. Chem. Commun. 2015, 51, 12365-12368. [CrossRef]

239. Zhang, S.; Sui, L.; Dong, H.; He, W.; Dong, L.; Yu, L. High-performance supercapacitor of graphene quantum dots with uniform sizes. ACS Appl. Mater. Interfaces 2018, 10, 12983-12991. [CrossRef]

240. Li, Z.; Cao, L.; Qin, P.; Liu, X.; Chen, Z.; Wang, L.; Pan, D.; Wu, M. Nitrogen and oxygen co-doped graphene quantum dots with high capacitance performance for micro-supercapacitors. Carbon N. Y. 2018, 139, 67-75. [CrossRef]

241. Ganganboina, A.B.; Dutta Chowdhury, A.; Doong, R.A. New avenue for appendage of graphene quantum dots on halloysite nanotubes as anode materials for high performance supercapacitors. ACS Sustain. Chem. Eng. 2017, 5, 4930-4940. [CrossRef]

242. Ganganboina, A.B.; Chowdhury, A.D.; Doong, R. An Nano assembly of N-doped graphene quantum dots anchored $\mathrm{Fe} 3 \mathrm{O} 4 /$ halloysite nanotubes for high performance supercapacitor. Electrochim. Acta 2017, 245, 912-923. [CrossRef]

243. Li, Z.; Qin, P.; Wang, L.; Yang, C.; Li, Y.; Chen, Z.; Pan, D.; Wu, M. Amine-enriched graphene quantum dots for high-pseudocapacitance supercapacitors. Electrochim. Acta 2016, 208, 260-266. [CrossRef]

244. Li, Z.; Li, Y.; Wang, L.; Cao, L.; Liu, X.; Chen, Z.; Pan, D.; Wu, M. Assembling nitrogen and oxygen co-doped graphene quantum dots onto hierarchical carbon networks for all-solid-state flexible supercapacitors. Electrochim. Acta 2017, 235, 561-569. [CrossRef]

245. Huang, Y.; Shi, T.; Zhong, Y.; Cheng, S.; Jiang, S.; Chen, C.; Liao, G.; Tang, Z. Graphene-quantum-dots induced $\mathrm{NiCo}_{2} \mathrm{~S}_{4}$ with hierarchical-like hollow nanostructure for supercapacitors with enhanced electrochemical performance. Electrochim. Acta 2018, 269, 45-54. [CrossRef]

246. Jia, H.; Cai, Y.; Lin, J.; Liang, H.; Qi, J.; Cao, J.; Feng, J.; Fei, W.D. Heterostructural Graphene Quantum Dot $/ \mathrm{MnO}_{2}$ Nanosheets toward High-Potential Window Electrodes for High-Performance Supercapacitors. Adv. Sci. 2018, 5, 1-10. [CrossRef]

247. Zhang, S.; Zhu, J.; Qing, Y.; Wang, L.; Zhao, J.; Li, J.; Tian, W.; Jia, D.; Fan, Z. Ultramicroporous carbons puzzled by graphene quantum dots: Integrated high gravimetric, volumetric, and areal capacitances for Supercapacitors. Adv. Funct. Mater. 2018, 28, 1805898. [CrossRef]

248. Wu, K.; Xu, S.; Zhou, X.; Wu, H. Graphene quantum dots enhanced electrochemical performance of polypyrrole as supercapacitor electrode. Dianhuaxue 2013, 19, 361-370.

249. Kharangarh, P.R.; Umapathy, S.; Singh, G.; Sharma, R.K.; Kumar, A. High-performance pseudocapacitor electrode materials: Cobalt (II) chloride-GQDs electrodes. Emerg. Mater. Res. 2017, 6, 227-233. [CrossRef]

250. Kharangarh, P.R.; Gupta, V.; Singh, A.; Bhardwaj, P.; Grace, A.N. An efficient pseudocapacitor electrode material with co-doping of iron (II) and sulfur in luminescent graphene quantum dots. Diam. Relat. Mater. 2020, 107, 107913. [CrossRef]

251. Zhang, S.; Zhu, J.; Qing, Y.; Fan, C.; Wang, L.; Huang, Y.; Sheng, R.; Guo, Y.; Wang, T.; Pan, Y.; et al. Construction of hierarchical porous carbon nanosheets from template-assisted assembly of coal-based graphene quantum dots for high performance supercapacitor electrodes. Mater. Today Energy 2017, 6, $36-45$. [CrossRef]

(C) 2020 by the authors. Licensee MDPI, Basel, Switzerland. This article is an open access article distributed under the terms and conditions of the Creative Commons Attribution (CC BY) license (http://creativecommons.org/licenses/by/4.0/). 